\title{
The Scarring Effect of Recessions
}

\author{
Min Ouyang*
}

November 4, 2005

\begin{abstract}
Recessions often coincide with intensified restructuring. The conventional Schumpeterian view argues that recessions promote allocative efficiency by driving out less productive firms and freeing resources for more productive uses. This paper proposes that the conventional cleansing effect is offset by a scarring effect. Recessions impede the development of potentially superior firms, which might put innovations to better uses, but which are destroyed during their infancy, and never realize their potential. A model of industry dynamics that combines Schumpeterian creative destruction with firm learning is developed to capture both the cleansing and scarring effects. Calibrating the model with data from the U.S. manufacturing sector demonstrates that the scarring effect is likely to dominate the cleansing effect, and accounts for the procyclicality of average labor productivity, a phenomenon at odds with conventional cleansing models.

Keywords: Business Cycles, Cleansing Effect, Scarring Effect, Creative Destruction, Learning, Job Flows.
\end{abstract}

JEL: E32, L16, C61

\footnotetext{
${ }^{*}$ University of California at Irvine, Department of Economics, 3151 Social Science Plaza B, Irvine, CA, 92697, mouyang@uci.edu.
} 
"[Depressions] are the means to reconstruct each time the economic system on a more efficient plan. But they inflict losses while they last, drive firms into the bankruptcy court...before the ground is clear and the way paved for new achievement..." Joseph A. Schumpeter (1934, p. 8)

"You must empty-out the bathing-tub, but not the baby along with it." Thomas Carlyle (1904, p. 368)

\section{Introduction}

With firms going bankrupt and workers getting laid off, recessions often coincide with intensified restructuring. Davis and Haltiwanger (1999) document sharp spikes in employment loss in major sectors of the economy during postwar U.S. recessions that largely reflects deaths of businesses. ${ }^{1}$ Schumpeter (1934) recognized these patterns decades earlier and proposed the concept of "cleansing": recessions are times when outdated techniques and products are driven out, and resources are freed for more productive uses; hence, notwithstanding the losses to particular businesses and individuals, recessions lead to greater allocative efficiency. This view has been revived recently by Hall (1992, 2000), Mortensen and Pissarides (1994), Caballero and Hammour (1994, 1996), and Gomes, Greenwood, and Rebelo (2001). ${ }^{2}$

However, as pointed out in Caballero and Hammour (1994), the cleansing effect alone contradicts empirical evidence in one important aspect - cleansing implies countercyclical productivity, while average labor productivity is in fact procyclical. Caballero and Hammour (1994, p.1365) further conjecture that the cleansing effect on productivity "is likely to be small and may be dwarfed by other factors". Subsequent theoretical work has supplemented the cleansing view from the creation side. Barlevy (2002) models on-the-job search and argues that during recessions, due to fewer vacancies, workers are having a more difficult time moving into jobs for which they are best suited. Thus, he suggests a "sullying effect" on the creation side playing against the cleansing effect on the destruction side. Although the existing evidence indicates that job destruction is more responsive to business cycles than job creation, ${ }^{3}$ the question remains, "Are the production units cleared

\footnotetext{
${ }^{1}$ The evidence is based on data that extend through 1993. Caballero and Hammour (2004) argue that recessions reduce rather than increase restructuring, but only cumulatively. In other words, they do not argue against that job destruction increases during recessions, but rather notice that often sluggish job creation follows. An extension of the current paper that can generate predictions consistent with their findings is discussed in the conclusion.

${ }^{2}$ These authors do not imply recessions lead to higher welfare. Higher allocation efficiency and lower welfare efficiency may co-exist during recessions.

${ }^{3}$ According to Davis and Haltiwanger (1999), job destruction is more volatile than job creation in manufacturing sectors of many economies. The variance of destruction divided by the variance of creation is 2.04 for the U.S., 1.49 for Canada, 1.0 for Denmark, 2.68 for the Netherlands, 1.69 for Germany, 0.68 in Colombia, and 18.19 for the U.K..
} 
by recessions necessarily the least productive?" If not, then recessions might exacerbate allocative inefficiency instead of alleviating it as the conventional cleansing view suggests. ${ }^{4}$

This paper proposes that, in addition to cleansing, recessions have a "scarring effect". The focus is on the destruction of young firms. We argue that while recessions drive out some of the least productive firms, they also kill off "potentially good firms": those that have the potential to be proven efficient in the future exit during recessions due to reduced profitability. The loss of potentially good firms leaves "scars" when a recession arrives, and the "scars" deepen as the recession persists. The presence of the scarring effect challenges the conventional view of recessions as periods of solely healthy reallocation: the overall impact of recessions on allocative efficiency should depend on the relative magnitude of two competing effects - cleansing and scarring.

To understand the scarring effect, consider a firm's life cycle. Often a firm starts without knowing itself how good it is. This may come from the unobservable talent of the manager, the unknown appeal for a product, or the unpredictable profitability of a store location. As the firm operates, realized revenue signals its true quality: high revenue suggests that the firm is more likely productive and encourages its continuing operation; low revenue suggests otherwise. A firm learns more and more as it grows older; once pessimistic enough, it chooses to exit. When a recession arrives, the profitability declines in general so that the firm cannot bear to learn as long as during good times. A potentially good firm that would have survived during good times, might thus exit during recessions before it learns. At the industry level, the exit of potentially good firms reduces the proportion of good firms at present times, as well as in the future because fewer potentially good firms are left to learn. The reduced proportion of good firms drives down the average productivity, which is defined in this paper as a scarring effect.

The above story reflects the spirit of firm learning, advanced theoretically by Jovanovic (1982) and suggested empirically as an important driving force for firm turnover. For example, Baldwin (1995), Balk and Gort (1993), Foster, Haltiwanger and Syverson (2005), Jensen, McGuckin and Stiroh (2000) present evidence showing that, in the US manufacturing sector, firms in each entering cohort differ in productivity; as the cohort ages, its average productivity rises but productivity dispersion declines. These patterns can be well explained by firm learning as described above, which motivates this paper to explore the interaction of learning with business cycles.

We combine learning with the vintage model of Caballero and Hammour (1994) to provide a framework that captures both cleansing and scarring effects. Firm-level productivity is decomposed into two components - vintage and unobservable idiosyncratic productivity - so that the indus-

\footnotetext{
${ }^{4}$ Ramey and Watson (1997) and Caballero and Hammour (2005) have both examined the efficiency of job destruction threshold. But they are motivated by whether the job destruction margin during recessions is socially efficient. Their cyclical implications on productivity are the same as in the models of the conventional cleansing effect: average job quality goes up during recessions.
} 
trial average productivity is determined by the distribution of firms across both dimensions. In equilibrium, firms' exit ages indicate the oldest vintages in operation, and the number of learning opportunities available, which in turn, determines the proportion of good firms. Demand variations serve as source of economic fluctuations. Lower demand reduces profitability in general so that firms' exit ages become younger. Younger exit ages directs, on the one hand, resources to younger and more productive vintages, causing a cleansing effect that raises average productivity; while, on the other hand, they truncate the learning process that directs resources toward good firms, creating a scarring effect that pulls down average productivity. Hence, recessions cause two competing effects - cleansing and scarring. The question then becomes, which effect dominates?

We turn to data on U.S. manufacturing job flows to explore the quantitative implications of the scarring effect. Our results suggest that, with reasonable calibration, the scarring effect dominates the cleansing effect in the U.S. manufacturing sector from 1972 to 1993, and can account for the observed procyclical average labor productivity.

Various studies of the U.S. manufacturing sector have provided wide support for our decomposition of firm-level productivity. ${ }^{5}$ The resulting two effects on resource reallocation - vintage and learning - have also been advanced empirically as powerful tools to understand the patterns of industrial dynamics. ${ }^{6}$ The significance of their interactions is noted by Davis and Haltiwanger (1999), "vintage effects may be obscured by selection effects; vintage and selection effects may also interact in important ways..." In our model, it is the interaction of these two effects, together with demand variations, that generates the scarring effect of recessions.

The rest of the paper is organized as follows. Section 2 lays out the model. The cleansing and scarring effects are motivated in Section 3 by analytical comparative static exercises. Section 4 applies the approach of Krusell and Smith (1998) to numerically solve the model with stochastic demand fluctuations, and studies its quantitative implications for productivity using data on U.S. manufacturing job flows. We conclude in Section 5 by discussing the model's extensions that generate predictions consistent with other authors' new findings.

\section{$2 \quad$ A Renovating Industry with Learning}

This section describes a learning industry that experiences exogenous technological progress. Firmlevel productivity is modeled to capture the empirical findings by Baldwin (1995), Balk and Gort (1993), Foster, Haltiwanger and Syverson (2005) that in the U.S. manufacturing sector, each entering cohort appears more productive than incumbents on average, and is itself a heterogeneous

\footnotetext{
${ }^{5}$ See Section 2.

${ }^{6}$ See Caves (1998) for an extensive review of findings on firm turnover and industrial dynamics.
} 
group in productivity.

\section{$2.1 \quad$ Firms}

Consider an industry where labor and capital combine in fixed proportions to produce a homogenous output. Firms that enter at different times may coexist. Each age cohort consists of a continuum of firms. A firm hires one worker, so that a job is created when a firm enters and a job is destroyed when a firm exits. Each firm is characterized by two components:

1. Vintage;

2. idiosyncratic productivity.

A firm's vintage is given by an exogenous technological progress $\left\{A_{t}\right\}_{0}^{\infty}$ that grows at a constant rate $\gamma>0$ so that

$$
A_{t}=A_{0} \cdot(1+\gamma)^{t}
$$

where $A_{0}$ is a constant. A firm enters the industry embodied with the leading technology. It becomes the firm's vintage and will affect its production afterward. We assume that, only entrants have access to the updated technology, incumbents cannot retool. Since technology grows exogenously, young firms are always technologically more advanced than old firms. With $a$ as the firm age, the vintage of a firm of age $a$ in period $t$ is $A_{t-a}$. Apparently:

$$
A_{t-a}=A_{0} \cdot(1+\gamma)^{t-a}
$$

At the time of entry, a firm is endowed with idiosyncratic productivity $\theta$. Hence, firms of the same vintage differ in idiosyncratic productivity. $\theta$ can represent the talent of the manager as in Lucas (1978), or alternatively, the location of the store, the organizational structure of the production process, or its fitness to the embodied technology. ${ }^{7}$ The key assumption regarding $\theta$ is that its value, although fixed at the time of entry, is not directly observable.

A firm of age $a$ and idiosyncratic productivity $\theta$ produces output in period $t$, according to

$$
q_{t}(a, \theta)=A_{t-a} \cdot x_{t}=A_{0} \cdot(1+\gamma)^{t-a} \cdot x_{t}
$$

where

$$
x_{t}=\theta+\varepsilon_{t} .
$$

\footnotetext{
${ }^{7}$ Since a firm is identical to a job under this set-up, $\theta$ can also be interpreted as "match quality." See Pries (2004).
} 
The shock $\varepsilon_{t}$ is an i.i.d. random draw from a fixed distribution that masks the influence of $\theta$ on output. We set the operating cost of a firm (including wages) to 1 by normalization, and let $P_{t}$ denote the output price in period $t$. Then the profit generated by a firm of age $a$ and idiosyncratic productivity $\theta$ in period $t$ is

$$
\pi_{t}(a, \theta)=P_{t} \cdot A_{0} \cdot(1+\gamma)^{t-a} \cdot\left(\theta+\varepsilon_{t}\right)-1
$$

Both $q_{t}(a, \theta)$ and $\pi_{t}(a, \theta)$ are directly observable. Since the firm knows its vintage, it can infer the value of $x_{t}$. The firm uses its observations of $x_{t}$ to learn about $\theta$.

\section{2 "All-Or-Nothing" Learning}

Firms are price takers and profit maximizers. They attempt to resolve the uncertainty about $\theta$ to decide whether to continue or terminate the production. The random component $\varepsilon_{t}$ represents transitory factors that are independent of the idiosyncratic productivity $\theta$. Assuming that $\varepsilon_{t}$ has mean zero, we have

$$
E_{t}\left(x_{t}\right)=E_{t}(\theta)+E_{t}\left(\varepsilon_{t}\right)=E_{t}(\theta)
$$

Given knowledge of the distribution of $\varepsilon_{t}$, a sequence of observations of $x_{t}$ allows the firm to learn about its $\theta$. Although a continuum of potential values for $\theta$ is more realistic, for simplicity it is assumed here that there are only two values: $\theta_{g}$ for a good firm and $\theta_{b}$ for a bad firm. Furthermore, $\varepsilon_{t}$ is assumed to be distributed uniformly on $[-\omega, \omega]$. Therefore, a good firm will have $x_{t}$ each period as a random draw from a uniform distribution over $\left[\theta_{g}-\omega, \theta_{g}+\omega\right]$, while the $x_{t}$ of a bad firm is drawn from an uniform distribution over $\left[\theta_{b}-\omega, \theta_{b}+w\right]$. Finally, $\theta_{g}, \theta_{b}$ and $\omega$ satisfy $0<\theta_{b}-\omega<\theta_{g}-\omega<\theta_{b}+\omega<\theta_{g}+\omega$.

Pries (2004) shows that the above assumptions give rise to an "all-or-nothing" learning process. With an observation of $x_{t}$ within $\left(\theta_{b}+\omega, \theta_{g}+\omega\right]$, the firm learns with certainty that it is a good idiosyncratic productivity; conversely, an observation of $x_{t}$ within $\left[\theta_{b}-\omega, \theta_{g}-\omega\right)$ indicates that it is a bad idiosyncratic productivity. However, an $x_{t}$ within $\left[\theta_{g}-\omega, \theta_{b}+\omega\right]$ does not reveal anything, since the probabilities of falling in this range as a good firm and as a bad firm are the same (both equal to $\left.\frac{2 \omega+\theta_{b}-\theta_{g}}{2 \omega}\right)$.

This all-or-nothing learning simplifies our model considerably. We let $\theta^{e}$ represent the expected $\theta$. Since it is $\theta^{e}$ instead of $\theta$ that affects firms' decisions, there are three groups of firms corresponding to the three values of $\theta^{e}$ : firms with $\theta^{e}=\theta_{g}$, firms with $\theta^{e}=\theta_{b}$, and firms with $\theta^{e}=\theta_{u}$, the prior mean of $\theta$. We define "unsure firms" as those with $\theta^{e}=\theta_{u}$. We further assume that the unconditional probability of $\theta=\theta_{g}$ is $\varphi$, and let $p \equiv \frac{\theta_{g}-\theta_{b}}{2 \omega}$ denote the probability of true 


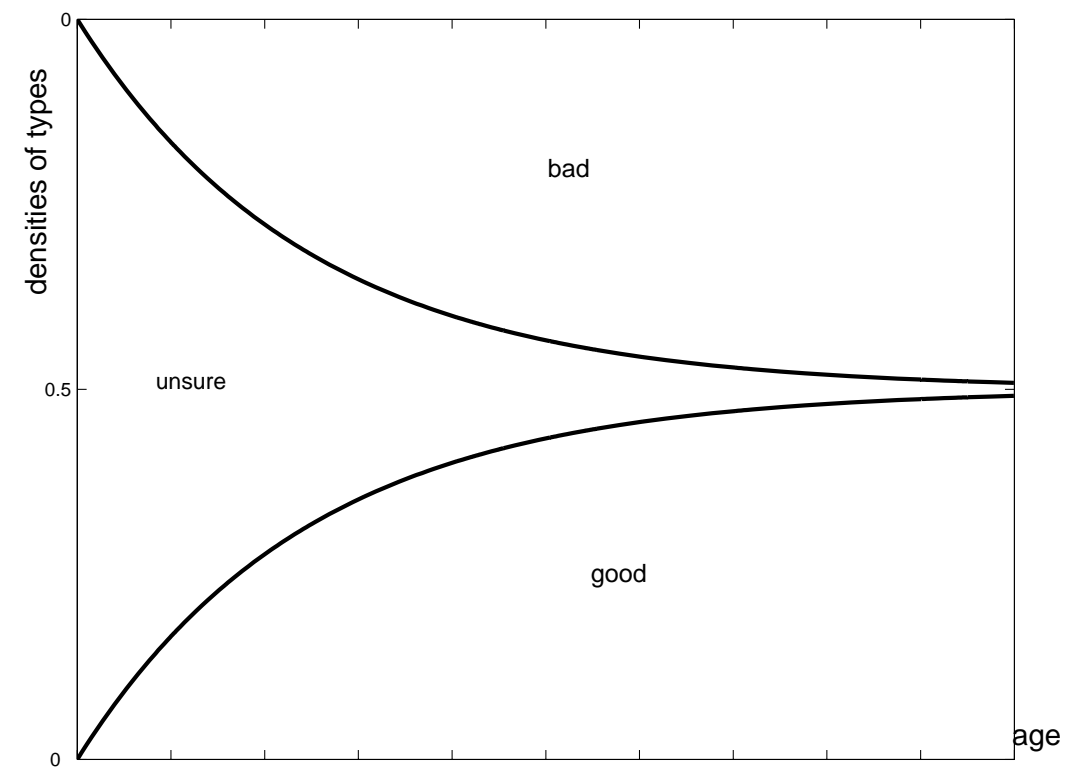

Figure 1: Dynamics of a Birth Cohort: the distance between the concave curve and the bottom axis measures the density of firms with $\theta^{e}=\theta_{g}$; the distance between the convex curve and the top axis measures the firms with $\theta^{e}=\theta_{b}$; the distance between the two curves measures the density of unsure firms (firms with $\theta^{e}=\theta_{u}$ ).

idiosyncratic productivity being revealed every period. Firms enter the market as unsure; thereafter, every period they stay unsure with probability $1-p$, learn they are good with probability $p \cdot \varphi$ and learn they are bad with probability $p \cdot(1-\varphi)$. Thus, the evolution of $\theta^{e}$ from the time of entry is a Markov process with values $\left(\theta_{g}, \theta_{u}, \theta_{b}\right)$, an initial probability distribution:

$$
(0,1,0)
$$

and a transition matrix

$$
\left(\begin{array}{ccc}
1 & 0 & 0 \\
p \cdot \varphi & 1-p & p \cdot(1-\varphi) \\
0 & 0 & 1
\end{array}\right)
$$

If firms were to live forever, eventually all uncertainty would be resolved because the market would provide enough information to reveal each firm's true idiosyncratic productivity. The limiting probability distribution as $a$ goes to $\infty$ is

$$
(\varphi, \quad 0,(1-\varphi))
$$


Because there is a continuum of firms, it is assumed that the law of large numbers applies, so that both $\varphi$ and $p$ are not only the probabilities but also the fractions of unsure firms with $\theta=\theta_{g}$, and of firms who learn $\theta$ each period, respectively. Hence, ignoring firm exit for now, we have the densities of three groups of firms in a cohort of age $a$ as

$$
\left(\varphi \cdot\left[1-(1-p)^{a}\right], \quad(1-p)^{a}, \quad(1-\varphi) \cdot\left[1-(1-p)^{a}\right]\right)
$$

which implies an evolution of cross-section firm distribution within a birth cohort as shown in Figure 1, with the horizontal axis depicting the age of a cohort across time. The densities of firms that are certain about their idiosyncratic productivity, whether good or bad, grow as a cohort ages. Moreover, the two "learning curves" (depicting the evolution of densities of good firms and bad firms) are concave. This feature is defined as the decreasing property of marginal learning in Jovanovic (1982): the marginal learning effect decreases with firm age, which in our model is reflected by the fact that the marginal number of learners decreases with cohort age. The convenient feature of all-or-nothing learning is that, on the one hand, it implies that any single firm learns "suddenly", which allows us to easily keep track of the cross-section distribution of beliefs, while on the other hand, it still implies "gradual learning" at the cohort level.

However, there is more that Figure 1 can tell. If we let the horizontal axis depict the crosssectional distribution of firm ages at any instant, then Figure 4 can be interpreted as the firm distribution across ages and idiosyncratic productivity of an industry that features constant entry but no exit. In this industry, cohorts continuously enter in the same size and experience the same dynamics afterward, so that at any one time, different life-stages of different birth cohorts overlap, giving rise to the distribution in Figure 4. Under this interpretation, Figure 4 indicates that at any instant older cohorts contain fewer unsure firms, because they have lived longer and learned more.

\subsection{The Recursive Competitive Equilibrium}

The following sequence of events is assumed to occur within a period. First, entry and exit occur after firms observe the aggregate state. Second, each surviving firm pays a fixed operating cost to produce. Third, the aggregate price is realized. Fourth, firms observe revenue and update beliefs. Then, another period begins.

With this setup, this subsection considers a recursive competitive equilibrium definition which includes as a key component the law of motion of the aggregate state of the industry. The aggregate state is $(F, D)$. $F$ denotes the distribution (measure) of firms across vintages and idiosyncratic productivity. The part of $F$ that measures the number of firms with belief $\theta^{e}$ and age $a$ is denoted $f\left(\theta^{e}, a\right) . \quad D$ is an exogenous demand parameter; it captures aggregate conditions and is fully 
observable. The law of motion for $D$ is exogenous, described by $D$ 's transition matrix. The law of motion for $F$ is denoted $H$ so that $F^{\prime}=H(F, D)$. The sequence of events implies that $H$ captures the influence of entry, exit and learning.

Three assumptions characterize the equilibrium: firm rationality, free entry and competitive pricing.

Firm Rationality: firms are assumed to have rational expectations; their decisions are forwardlooking. Firms need to observe $(F, D)$ to predict the sequence of prices from today onward. Therefore, the relevant state variables for a firm are its vintage, its belief about its true idiosyncratic productivity, and the aggregate state $(F, D)$. We let $V\left(\theta^{e}, a ; F, D\right)$ be the expected value, for a firm with belief $\theta^{e}$ and age $a$, of staying in operation for one more period and optimizing afterward, when the aggregate state is $(F, D)$. Then $V$ satisfies:

$$
V\left(\theta^{e}, a ; F, D\right)=E\left[\pi\left(\theta^{e}, a\right) \mid F, D\right]+\beta E\left[\max \left(0, V\left(\theta^{e \prime}, a+1 ; F^{\prime}, D^{\prime}\right)\right) \mid F, D\right]
$$

subject to

$$
F^{\prime}=H(F, D)
$$

and the exogenous laws of motion for $D$ and $\theta^{e}$ (driven by all-or-nothing learning).

Since firms enter as unsure, firm rationality implies that entry occurs if and only if $V\left(\theta_{u}, 0 ; F, D\right)>$ 0 . Meanwhile, a firm with belief $\theta^{e}$ and age $a$ exits if and only if $V\left(\theta^{e}, a ; F, D\right)<0$.

Free entry: new firms are free to enter at any instant, each bearing an entry cost $c$. The entry cost can be interpreted as the cost of establishing a particular location or the cost of finding a manager. Assuming $f\left(\theta_{u}, 0 ; F, D\right)$ represents the size of the entering cohort when the aggregate state is $(F, D)$, and letting $c$ represent the entry cost, we have

$$
c=C\left(f\left(\theta_{u}, 0 ; F, D\right)\right), c>0 \text { and } C^{\prime} \geq 0
$$

I let the entry cost depend positively on the entry size to capture the idea that, for the industry as a whole, fast entry is costly and adjustment may not take place instantaneously. This can arise from a limited amount of land available to build production sites or an upward-sloping supply curve for the industry's capital stock. ${ }^{8}$ The free entry condition equates a firm's entry cost to its value of entry, and can be written as

$$
V\left(\theta_{u}, 0 ; F, D\right)=C\left(f\left(\theta_{u}, 0 ; F, D\right)\right)
$$

As more new firms enter, the entry cost is driven up until it reaches the value of entry. At this

\footnotetext{
${ }^{8}$ See the next section for further discussion.
} 
point, entry stops.

Competitive Pricing: the output price is competitive; the price level is given by

$$
P(F, D)=\frac{D}{Q(F, D)}
$$

$Q$ represents aggregate output; it equals the the sum of production over heterogeneous firms. Given (3.1), the sequence of events implies that: ${ }^{9}$

$$
Q(F, D)=Q\left(F^{\prime}\right)=A \sum_{a} \sum_{\theta^{e}}(1+\gamma)^{-a} \cdot \theta^{e} \cdot f^{\prime}\left(\theta^{e}, a\right)
$$

where $A$ represents the industry leading technology when the aggregate state is $(F, D) . f^{\prime}\left(\theta^{e}, a\right)$ measures the number of operating firms with $\theta^{e}$ and a after entry and exit. $f^{\prime}\left(\theta^{e}, a\right)$ belongs to $F^{\prime}$, the updated firm distribution. Since $F^{\prime}=H(F, D), Q$ is a function of $(F, D)$.

(6) implies that high output drives down the price. (7) implies that $Q$ depends not only on the number of firms in operation, but also on their distribution. More firms yield higher output and drive down the price; the more the distribution is skewed toward younger vintages and better idiosyncratic productivity, the higher the output and the lower the price.

With the above three conditions, we have the following:

Definition: A recursive competitive equilibrium is a law of motion $H$, a value function $V$, and a pricing function $P$ such that $(i) V$ solves the firm's problem; (ii) $P$ satisfies (6) and (7); and (iii) $H$ is generated by the decision rules suggested by $V$ and the appropriate summing-up of entry, exit and learning.

An additional assumption is made to simplify the model:

Assumption: Given values for other parameters, the value of $\theta_{b}$ is so low that $V\left(\theta_{b}, a ; F, D\right)$ is negative for any $(F, D)$ and $a$.

This assumption implies that bad firms always exit, so that at any one time, there are only two types of firms in operation - unsure and good.

\footnotetext{
${ }^{9} Q$ is the sum of realized output rather than expected output, since the contribution to aggregate output by each firm depends on its true type $\theta$ rather than $\theta^{e}$. However, with a continuum of firms, the law of large numbers implies that the random noises and the expectation errors cancel out in each cohort, so that the sum of realized output equals the sum of expected output.
} 


\section{Cleansing and Scarring}

This section motivates the cleansing and scarring effects. The previous section shows that the firm distribution $F$ enters the model as a state variable, which makes it difficult to characterize the dynamics generated by demand fluctuations. However, similar studies find that the effects of temporary changes in aggregate conditions are qualitatively similar to the effects of permanent changes. ${ }^{10}$ Therefore, we exercise in this section comparative statics on the steady-state equilibrium. The comparative static exercises capture the essence of industry dynamics as well as how demand can affect the labor allocation, and thus provide a more rigorous intuition for the scarring and cleansing effects described in the introduction. In the next section, we will turn to a numerical analysis of the model's response to stochastic demand fluctuations and confirm that the results from the comparative static exercises carry over.

\subsection{The Steady State}

I define a steady state as a recursive competitive equilibrium with time-invariant aggregate states. ${ }^{11}$ It satisfies two additional conditions: $D$ is and is perceived as time-invariant: $D^{\prime}=D ; F$ is timeinvariant: $F^{\prime}=H(F, D)$. Since $H$ is generated by entry, exit and learning, a steady state must feature time-invariant entry and exit for $F=H(F, D)$ to hold. Thus, it can be summarized by $\left\{f(0), \bar{a}_{g}, \bar{a}_{u}\right\}$, with $f(0)$ as the entry size, $\bar{a}_{g}$ as the maximum age for good firms, and $\bar{a}_{u}$ as the maximum age for unsure firms. The next proposition establishes the existence of a unique steady-state equilibrium. The proof is presented in the appendix.

Proposition 1: With D constant over time, there exists a unique time-invariant $\left\{f(0), \bar{a}_{g}, \bar{a}_{u}\right\}$ that satisfies the conditions of firm rationality, free entry and competitive pricing.

The steady-state labor distribution and job flows are illustrated in Figure 2. Like Figure 1, there are two ways to interpret Figure 2. First, it displays the steady-state life-cycle dynamics of a representative cohort with the horizontal axis depicting the cohort age across time. Firms enter in size $f(0)$ as unsure. As the cohort ages and learns, bad firms are thrown out so that the cohort size declines; good firms are realized, so that the density of good firms increases. After age $\overline{a_{u}}$, all unsure firms exit because their vintage is too old to survive with $\theta^{e}=\theta_{u}$. However, firms with $\theta^{e}=\theta_{g}$ stay. Afterwards, the cohort contains only good firms and the number of good firms remains constant because learning has stopped. Good firms live until $\overline{a_{g}}$. The vintage after $\overline{a_{g}}$ is too old even for good firms to survive.

\footnotetext{
${ }^{10}$ See Mortensen and Pissarides (1994), Caballero and Hammour (1994 and 1996), and Barlevy (2002).

${ }^{11}$ The term "steady state" follows Caballero and Hammour (1994). Despite its name, the steady-state price decreases while the steady-state average labor productivity increases over time due to technological progress.
} 


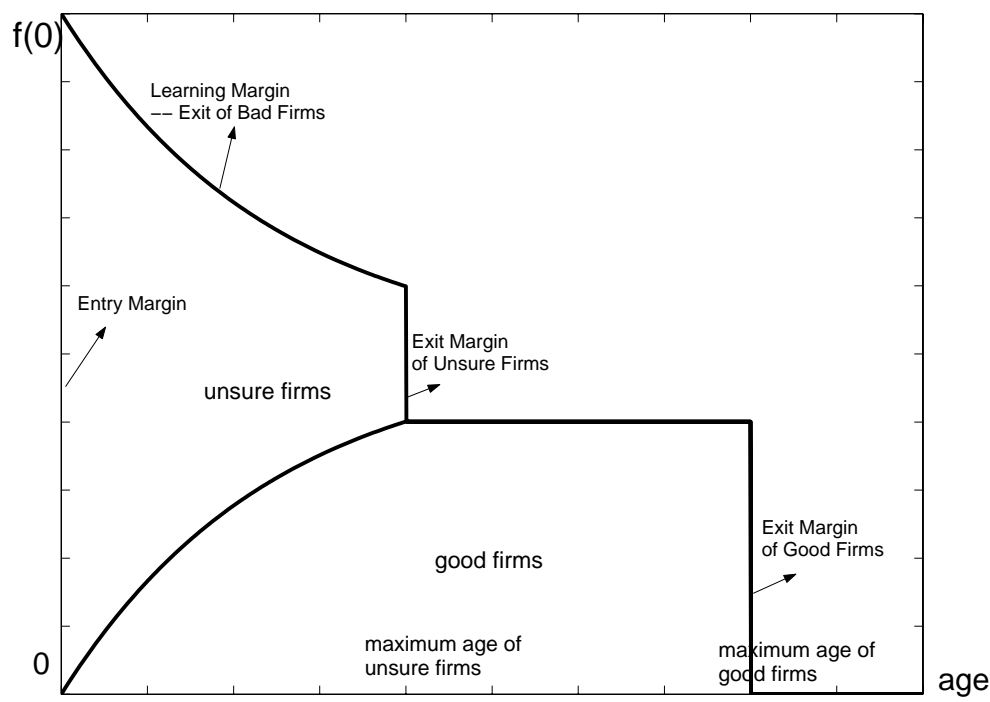

Figure 2: The Steady-state Labor Distribution and Job Flows: the distance between the lower curve (extended as the horizontal line) and the bottom axis measures the density of good firms; the distance between the two curves measures the density of unsure firms. 
Second, Figure 2 also displays the firm distribution across ages and idiosyncratic productivity at any one time, with the horizontal axis depicting the cohort age cross section. At the steady state, firms of different ages coexist. Since older cohorts have lived longer and learned more, their size is lower and their density of good firms is higher. Cohorts older than $\overline{a_{u}}$ are of the same size and contain only good firms. No cohort is older than $\overline{a_{g}}$.

Notice that, despite its time-invariant structure, the industry experiences continuous entry and exit. With entry, jobs are created; with exit, jobs are destroyed. From a pure accounting point of view, there are three margins for job flows: the entry margin, the exit margins of good firms and unsure firms, and the learning margin. At the entry margin, new vintages enter. At the exit margins, old vintages leave. At the learning margin, bad firms are selected out. Because of creative destruction, average labor productivity grows at the technological pace $\gamma$. Because of learning, the productivity distribution among older cohorts is more skewed toward good firms. For cohorts older than $\overline{a_{u}}$, labor is employed only at good firms.

\subsection{Comparative Statics: Cleansing and Scarring}

In this subsection, we establish that across steady states corresponding to different demand levels, the model delivers the conventional cleansing effect promoted in the previous literature, as well as an additional scarring effect. The two effects are formalized in Propositions 2 and 3. The intuitions are captured in Figure 3, which displays the steady-state industry structures corresponding to a high demand and a low demand. ${ }^{12}$

Proposition 2: In a steady-state equilibrium, the exit age for firms with a given belief is weakly increasing in the demand level and the job destruction rate is weakly decreasing in the demand level.

A detailed proof is included in the appendix. Proposition 2 argues that the steady state with a lower demand features younger exit ages. This is shown in Figure 3 as the leftward shift of the two exit margins corresponding to a lower demand level. Moreover, the steady-state job destruction

\footnotetext{
${ }^{12}$ The entry sizes of the two steady states, although different, are normalized as 1 . Since the steady state features time-invariant entry and all cohorts are the same size, entry size matters only as a scale.
} 
rate, denoted $j d^{s s}$, equals the following: ${ }^{13}$

$$
j d^{s s}=\frac{1}{\overline{a_{u}} \cdot \varphi+\left[\frac{1-\varphi}{p}+\left(\overline{a_{g}}-\overline{a_{u}}\right) \cdot \varphi\right] \cdot\left[1-(1-p)^{\overline{a_{u}}+1}\right]} .
$$

I prove in the appendix that $\frac{d\left(j d^{s s}\right)}{d(D)} \leq 0$. Put intuitively, a high-demand steady state allows both unsure firms and good firms to live longer, so that fewer jobs are destroyed at the exit margins. In other words, lower demand tends to drive down the price so that some firms that are viable in a high-demand steady state are not viable when demand is low.

If this story carries over when $D$ fluctuates stochastically over time, then our model delivers a conventional "cleansing" effect, in which average firm age falls during recessions so that recessions direct resources to younger, more productive vintages. However, once learning is allowed, we also need to take into account the allocation of labor across idiosyncratic productivity. With only two true idiosyncratic productivity, good and bad, the idiosyncratic productivity distribution of labor can be summarized by the fraction of labor at good firms. A higher fraction suggests a more efficient allocation of labor. The next proposition establishes how the level of demand affects this ratio in a steady state.

Proposition 3: In a steady state equilibrium, the fraction of labor at good firms is weakly increasing in the demand level.

It can be shown that the steady-state fraction of labor at good firms, denoted $l_{g}^{s s}$, equals:

$$
l_{g}^{s s}=1-\frac{(1-\varphi)}{\frac{p \varphi \overline{a_{u}}}{1-(1-p)^{\overline{a_{u}}}}+(1-\varphi)+p \varphi\left(\overline{a_{g}}-\overline{a_{u}}\right)} .
$$

In the appendix, we prove that demand affects $l_{g}^{s s}$ only through its impact on $\overline{a_{u}}$ so that $\frac{d\left(l_{g}^{s s}\right)}{d(D)}=$ $\frac{d\left(l_{g}^{s s}\right)}{d\left(\overline{a_{u}}\right)} \cdot \frac{d\left(\overline{a_{u}}\right)}{d(D)}$. we also prove $\frac{d\left(l_{g}^{s s}\right)}{d\left(\overline{a_{u}}\right)} \geq 0$, which, together with $\frac{d\left(\overline{a_{u}}\right)}{d(D)} \geq 0$ suggested by Proposition 2 , implies $\frac{d\left(l_{g}^{s s}\right)}{d(D)} \geq 0$.

My analysis suggests that the impact of demand on the fraction of labor at good firms comes from its impact on the exit age of unsure firms. To understand this result intuitively, consider Figure 3.

\footnotetext{
${ }^{13}$ According to Davis and Haltiwanger (1992), for a given population of plants, the job destruction rate in a period is defined as the total number of jobs lost since the previous period at plants that decreased employment, divided by the average of total employment in the current and previous periods. With constant total number of jobs, the steady-state job destruction rate equals the ratio of jobs destroyed at the learning and exit margins over the total number of jobs. The expression of $j d^{s s}$ applies not only to a steady state, but also to any industry equilibrium that features time-invariant entry and exit. See Subsection 4.2 for further discussions on $j d^{s s}$.
} 


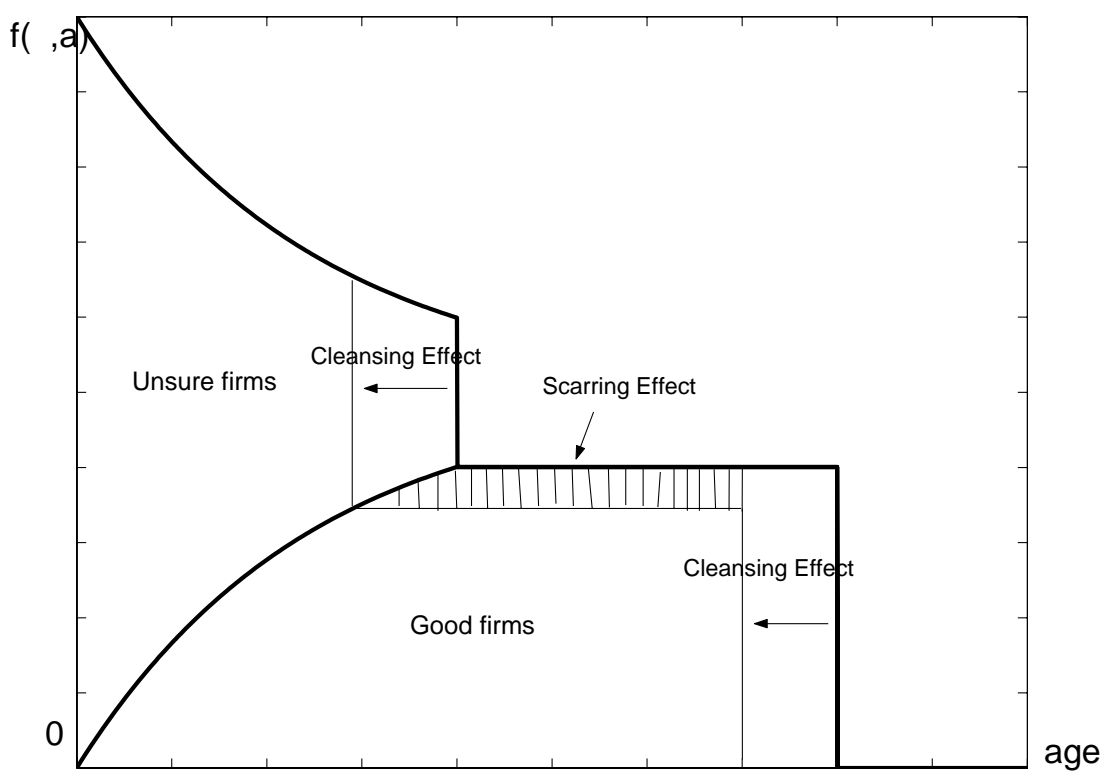

Figure 3: Cleansing and Scarring

In Figure 3, because of the cleansing effect, the two exit margins shift to the left corresponding to a lower demand. The shifted margins clear out old firms that could be either good or unsure. However, the leftward shift of the unsure exit margin also reduces the number of older good firms. The latter effect, shown as the shaded area in Figure 3, is the scarring effect of recessions.

The scarring effect stems from learning. New entrants begin unsure of their idiosyncratic productivity, although a proportion $\varphi$ are truly good. Over time, more and more bad firms leave while good firms stay. Since learning takes time, the number of "potentially good firms" that realize their true idiosyncratic productivity depends on how many learning chances they have. If firms could live forever, eventually all the potentially good firms would get to realize their true idiosyncratic productivity. But a finite life span of unsure firms implies that if potentially good firms do not learn before age $\bar{a}_{u}$, they exit and thus forever lose the chance to learn. Therefore, $\bar{a}_{u}$ represents not only the exit age of unsure firms, but also the number of learning opportunities. A low $\overline{a_{u}}$ allows potentially good firms fewer chances to realize their true idiosyncratic productivity, so that the number of old good firms in operation after age $\overline{a_{u}}$ is also reduced.

Hence, the industry suffers from uncertainty; it tries to select out bad firms but the group of firms it clears at age $\overline{a_{u}}$ includes some firms that are truly good. The number of clearing mistakes the industry makes at $\overline{a_{u}}$ depends on the size of the unsure exit margin, which in turn depends 
on the value of $\bar{a}_{u} .{ }^{14}$ When a drop in demand reduces the value of $\bar{a}_{u}$, this reduces the number of learning opportunities, allows fewer good firms to become old and thus shifts the labor distribution toward bad firms.

To summarize from Propositions 2 and 3, a low-demand steady state features a better average vintage, yet a less efficient cross-idiosyncratic productivity distribution of labor. If the comparative static results carry over when demand fluctuates stochastically, then recessions will have both a conventional cleansing effect, shifting resources to better vintages, and a scarring effect, shifting resources to bad idiosyncratic productivity. The two effects are directly related to each other: it is the cleansing effect that significantly reduces learning opportunities and hence prevents more firms from realizing their potential.

When we move beyond steady states to allow for cyclical fluctuations, the intuition behind "cleansing and scarring" still carries over. Again, consider Figure 3. Both exit margins shift as soon as demand drops so that the cleansing effect takes place immediately. ${ }^{15}$ However, the scarring effect takes place gradually. When a recession first arrives, the group of firms already in the shaded area in Figure 3 will not leave despite the shift in exit margins, since they know their true idiosyncratic productivity to be good. They leave gradually as the recession persists. At this point, the scarring effect starts to take place: the reduced $\overline{a_{u}}$ allows fewer good firms to survive past $\overline{a_{u}}$. The shaded area would eventually be left blank, and the "scar" left by recessions would surface.

\subsection{Sensitivity Analysis}

Before we turn to the numerical analysis to characterize the transitional dynamics, we close this section with two modifications of the model to check the robustness of our results from the comparative static exercises.

First, we allow the entry cost to be independent of entry size. In our model, $C$ is assumed to depend positively on entry size, so that a lower demand is accommodated by both less entry and more exit. But the entry margin may exclusively accommodates demand fluctuations. This extreme case is defined as the "full-insulation" case in Caballero and Hammour (1994). They argue that it occurs when $C^{\prime}\left(f\left(\theta_{u}, 0\right)\right)=0$. The intuition is as follows. If entry cost is independent of entry size, then fast entry is costless and the adjustment on the entry margin becomes instantaneous. When demand falls, entry will adjust to such a level that aggregate output falls by the same proportion, which keeps price at the same level. Then the value of staying remain unaffected, and the exit margins do not respond. The "full-insulation" case when $C^{\prime}\left(f\left(\theta_{u}, 0\right)\right)=0$ is also present in our

\footnotetext{
${ }^{14}$ The all-or-nothing learning suggests that the number of truly good firms cleared out at $\overline{a_{u}}$ equals $f(0)(1-p)^{\overline{a_{u}}} \varphi$.

${ }^{15} \mathrm{My}$ numerical exercises imply that when demand falls, these margins initially shift more than suggested by the comparative static exercises. The margins shift back partially as the recession persists. A detailed discussion of this phenomenon is contained in Section 4.
} 
model. ${ }^{16}$ Hence, with entry cost independent of entry size, there is neither a cleansing effect nor $a$ scarring effect.

However, in reality, an industry may not be able to create all the necessary production units instantaneously. Goolsbee (1998) shows empirically that higher investment demand drives up both the equipment prices and the wage of workers producing the capital goods. His findings suggest that as more firms enter and increase the demand for capital, it becomes increasingly costly to purchase capital. Therefore, $C^{\prime}\left(f\left(\theta_{u}, 0\right)\right)>0$ seems more reasonable. Furthermore, data does not support the assumption that $C^{\prime}\left(f\left(\theta_{u}, 0\right)\right)=0$. In the full-insulation case, job creation fully accommodates demand fluctuations and job destruction does not respond. This contradicts the large and robust evidence of highly volatile job destruction across sectors and economies.

Second, we allow the process of learning to be more complicated than "all-or-nothing" to see if the scarring effect still carries over. To look at the scarring effect from a different angle, suppose we divide firms into two groups, young and old. ${ }^{17}$ With $l_{g}^{o}$ denoting the fraction of labor at good firms among the old, $l_{g}^{y}$ as the fraction among the young, $f^{y}$ as the density of young firms and $f^{o}$ as the density of old firms, the fraction of labor at good firms for the industry as a whole, $l_{g}$, can be written as:

$$
l_{g}=\frac{f^{y} l_{g}^{y}+f^{o} l_{g}^{o}}{f^{y}+f^{o}}=\frac{l_{g}^{y}+l_{g}^{o} \frac{f^{o}}{f^{y}}}{1+\frac{f^{o}}{f^{y}}} .
$$

The first order derivative of $l_{g}$ with respect to $\frac{f^{o}}{f^{y}}$ equals:

$$
\frac{d\left(l_{g}\right)}{d\left(\frac{f^{o}}{f^{y}}\right)}=\frac{l_{g}^{o}-l_{g}^{y}}{1+\frac{f^{o}}{f^{y}}} .
$$

which is greater than or equal to zero as long as $l_{g}^{o}-l_{g}^{y} \geq 0$. Since old firms have experienced more learning, $l_{g}^{o}-l_{g}^{y} \geq 0$ should hold for any learning process. Hence, the scarring effect of recessions occurs regardless of the learning process, as long as recessions reduce the ratio of old to young firms $\left(\frac{f^{o}}{f^{y}}\right)$, which by definition will be true in any model in which recessions cleanse the economy of older vintages. Intuitively, recessions shift resources toward younger firms, so that there cannot be as much learning taking place as in booms. Although this analysis is preliminary, we can still argue that recessions would allow for less firm learning, so the scarring effect would carry over even with a more complicated process of learning. ${ }^{18}$

\footnotetext{
${ }^{16}$ It is discussed in the proof for Proposition 2. See the appendix.

${ }^{17}$ The cut-off age to define "young" and "old" is arbitrarily chosen. Changing this cut-off age does not affect the analysis that follows.

${ }^{18}$ To be more specific, suppose we assume a more complicated learning process with normally distributed random noise, so that the signals received by good firms are normally distributed around $\theta_{g}$ and the signals received by bad firms are normally distributed around $\theta_{b}$. In that case, a firm can never know for certain that it is good or bad, and
} 


\section{Quantitative Implications with Stochastic Demand Fluctuations}

This section applies numerical techniques to analyze a stochastic version of our model in which the demand level follows a two-state Markov process with values $\left[D_{h}, D_{l}\right]$ and transition probability $\mu$. Throughout this section, firms expect the current demand level to persist for the next period with probability $\mu$, and to change with probability $1-\mu$.

The key computational task is to map $F$, the firm distribution across ages and idiosyncratic productivity, given demand level $D$, into a set of value functions $V\left(\theta^{e}, a ; F, D\right)$. Unfortunately, the endogenous state variable $F$ is a high-dimensional object. The numerical solution of dynamic programming problems becomes increasingly difficult as the size of the state space increases. Our computational strategy follows Krusell and Smith (1998) by shrinking the state space into a limited set of variables and showing that these variables' laws of motion can approximate the equilibrium behavior of firms in the simulated time series. Details are presented in the appendix.

With approximated laws of motion, we first confirm that the basic insights from the comparative static exercises carry over with probabilistic business cycles. Then we examine whether the scarring effect is likely to be empirically relevant. Specifically, we calibrate our model so that its equilibrium job destruction rate mimics the observed pattern in the data. As we have argued, recessions clear out old firms, including some good firms that have not yet learned their type. Therefore, the model allows us to use the job destruction rate to make inferences on the size of the cleansing and scarring effects.

\subsection{Calibration}

Table 1 presents the assigned parameter values. Some of the parameter values are pre-chosen. The most significant in this group are the relative productivity of good and bad firms. We follow Davis and Haltiwanger (1999), who assume a ratio of high-to-low productivity of 2.4 for total factor productivity and 3.5 for labor productivity based on the between-plant productivity differentials reported by Bartelsman and Doms (1997). Since labor is the only input in our model, we normalize productivity of bad firms as 1 and set productivity of good firms as 3.5. We allow a period to represent one quarter and set the quarterly discount factor $\beta=0.99$. Next, we need to choose $\gamma$, the quarterly pace of technological progress. In a model with only creative destruction, Caballero

posterior beliefs are distributed continuously between $\theta_{b}$ and $\theta_{g}$. The expected value of staying would still depend positively on $\theta^{e}$ and negatively on age. Thus, given the aggregate state, there would be a cut-off age for each belief, $\bar{a}\left(\theta^{e} ; F, D\right)$, such that firms with belief $\theta^{e}$ do not live beyond $\bar{a}\left(\theta^{e} ; F, D\right)$.

With a recession, the value of staying across all ages and idiosyncratic productivity falls, so that for each belief $\theta^{e}$, the cut-off age $\bar{a}\left(\theta^{e} ; F, D\right)$ becomes younger. Hence, the firm distribution tilts toward younger ages and $\frac{f^{o}}{f^{y}}$ falls. Since $\frac{d\left(l_{g}\right)}{d\left(\frac{f^{o}}{f^{y}}\right)} \geq 0$, a fall in $\frac{f^{o}}{f^{y}}$ drives down the ratio of good firms and creates the scarring effect. 


\begin{tabular}{|c|c|}
\hline parameters (pre-chosen) & value \\
\hline productivity of bad firms: $\theta_{b}$ & 1 \\
\hline productivity of good firms: $\theta_{g}$ & 3.5 \\
\hline quarterly technological pace: $\gamma$ & 0.007 \\
\hline quarterly discount factor: $\beta$ & 0.99 \\
\hline parameters (calibrated) & value \\
\hline high demand: $D_{h}$ & 9969.2 \\
\hline low demand: $D_{l}$ & 6973.1 \\
\hline prior probability of being a good firm: $\varphi$ & 0.142 \\
\hline quarterly pace of learning: $p$ & 0.08 \\
\hline persistence rate of demand: $\mu$ & 0.58 \\
\hline entry cost function & $0.405+0.52 * f\left(0, \theta_{u}\right)$ \\
\hline
\end{tabular}

Table 1: Base-line Parameterization of the Model

and Hammour (1994) choose the quarterly technological growth rate as 0.007 by attributing all output growth of US manufacturing from the second quarter of1972 to the fourth quarter of 1983 to technical progress. To make comparison with their results convenient in the coming subsections, we also choose $\gamma=0.007$. Caballero and Hammour (1994) estimate the entry cost function by matching the job creation series of US manufacturing from 1970 to 1989 . Their result is applied here as $C=0.405+0.52 * f\left(0, \theta_{u}\right)$ with $f\left(0, \theta_{u}\right)$ representing the size of entry.

The remaining undetermined parameters are: $p$, the pace of learning; $\varphi$, the probability of being a good firm; $D_{h}$ and $D_{l}$, the demand levels; $\mu$, the probability with which demand persists; and $c_{0}$ and $c_{1}$, the entry cost parameters. The values of these parameters are chosen so that the job destruction series in the calibrated model matches properties of the historical series from the U.S. manufacturing sector. Davis and Haltiwanger (1999) shows that the U.S. manufacturing job destruction rates from the second quarter of 1972 to the fourth quarter of 1993 fluctuates between $2.96 \%$ and $11.60 \%$ with a mean of $5.6 \%$ and a standard deviation of $1.66 \%$. This put the following restrictions on our calibrated model.

First, its implied long-run job destruction rate must be around 5.6\%. Our numerical simulations suggest that the dynamic system eventually settles down with constant entry and exit along any sample path where the demand level is unchanging. The industry structures at these stable points are similar to those at the steady states, which allows us to use steady state conditions for approximation. ${ }^{19}$ We let $\overline{a_{g}}$ and $\overline{a_{u}}$ represent the maximum ages of good firms and unsure firms at the high-demand steady state and ${\overline{a_{g}}}^{\prime}$ and ${\overline{a_{u}}}^{\prime}$ represent the exit ages at the low-demand steady state. The steady-state job destruction rate implied by either pair, has to be around $5.6 \%$.

\footnotetext{
${ }^{19}$ However, a stable point is different from a steady state. In a steady state, firms perceive demand as constant, while in a stable point, firms perceive demand to persist with probability $\mu$, and to change with probability $1-\mu$.
} 
Second, we match the peak in job destruction that occurs at the onset of a recession. Our model suggests that the jump in the job destruction rate at the beginning of a recession comes from the shift of exit margins to younger ages. We assume that when demand drops, the exit margins shift from $\overline{a_{g}}$ and $\overline{a_{u}}$ to ${\overline{a_{g}}}^{\prime}$ and ${\overline{a_{u}}}^{\prime}$ immediately, and the job destruction rate at this moment must not exceed $11.6 \% .^{20}$

Third, we match the trough in job destruction that occurs at the onset of a boom. Our model suggests that when demand goes up, the exit margins extend to older ages, so that for several subsequent periods job destruction comes only from the learning margin, implying a trough in the job destruction rate. To match the data, the job destruction rate at this moment has to be around $3 \%$.

Additionally, $\left(\overline{a_{g}}, \overline{a_{u}}\right)$ and $\left({\overline{a_{g}}}^{\prime},{\overline{a_{u}}}^{\prime}\right)$ must satisfy steady state conditions on the gap between the exit ages of good and unsure firms. In total, there are six equations to pin down the values of six parameters. ${ }^{21}$ Using a search algorithm, we find that these conditions are satisfied for the following combination of parameter values: $p=0.08, \varphi=0.142, \overline{a_{g}}=78, \overline{a_{u}}=64,{\overline{a_{g}}}^{\prime}=73,{\overline{a_{u}}}^{\prime}=59$. By applying these $\overline{a_{g}}, \overline{a_{u}},{\overline{a_{g}}}^{\prime}$ and ${\overline{a_{u}}}^{\prime}$ to the steady state industry structure, we find $D_{h}=9969.2$ and $D_{l}=6973.1$.

The value of $\mu$ is calibrated to match the observed standard deviation of the job destruction rate of $1.66 \%$. In our model, the job destruction rate jumps above its mean when demand drops and falls below when demand rises. Thus, the frequency of demand switches between $D_{h}$ and $D_{l}$ determines the frequency with which the job destruction rate fluctuates between $11.6 \%$ and $3 \%$, which in turn affects the standard deviation of the simulated job destruction series. Our calibration exercises suggest $\mu=0.58$.

\subsection{Response to a Negative Demand Shock and Simulations of U.S. Manufac- turing Job Flows}

With all of the parameter values assigned, we approximate firms' value functions applying the computational strategy that follows Krusell and Smith (1998). With the approximated value functions, the corresponding decision rules, and an initial firm distribution, we can investigate the dynamics of our model's key variables along any particular path of demand realizations, and study the model's quantitative implications.

\footnotetext{
${ }^{20}$ As I have noted earlier, the calibration exercises suggest that when a negative aggregate demand shock strikes, the exit margins shift more than ${\overline{a_{g}}}^{\prime}$ and ${\overline{a_{u}}}^{\prime}$. The bigger shift implies a bigger jump in job destruction, This is why I require $n e g_{\max }$ to lie below $11.60 \%$. I experiment with different demand levels to find those that generate the closest fit.

${ }^{21}$ These equations are availble upon request.
} 


\subsubsection{Scarring and Cleansing over the Cycle}

To assess the effect of a negative demand shock, we start with a random firm distribution and simulate our model with demand level equal to $D_{h}$ for the first 200 quarters. Regardless of the initial firm distribution, we find that the exit age of good firms settles down to 76 , the exit age of unsure firms settles down to 61 , the job destruction rate converges to $5.38 \%$, and the fraction of good firms converges to $49.8 \%$. This suggests that our model is globally stable. Once the key variables converge, we simulate the effects of a negative demand shock that persists for the next 87 quarters.

The dynamics of the job destruction rate and the job creation rate are illustrated in Panel 1 of Figure 4, with the quarter labeled 0 denoting the onset of a recession. The job destruction rate goes up from $5.38 \%$ to $10.84 \%$ on impact. Thus, the immediate effect of a negative demand shock is to clear out some firms that would have stayed in had demand remained high. After 70 quarters, the job destruction rate converges to $5.63 \%$, still above its original value. Hence, the conventional cleansing effect of demand on job destruction that we establish analytically in steady state carries over with probabilistic cycles.

Unlike the job destruction rate, the job creation rate drops from $4.69 \%$ to $4.32 \%$ when a recession strikes, rises gradually and converges later. This matches the finding of Davis and Haltiwanger (1992) that the job creation rate falls during recessions and co-moves negatively with the job destruction rate over the cycle. ${ }^{22}$

The analysis of the steady state also suggests that recessions will bring a scarring effect by shifting labor resources toward bad firms. As shown in Panel 2 of Figure 4, the fraction of labor at good firms drops from $49.8 \%$ to $48.07 \%$ when the negative demand shock strikes and converges to $47.87 \%$ after 70 quarters. This implies that the negative demand shock shifts the cross-idiosyncratic productivity firm distribution toward bad firms. Hence, the scarring effect suggested by the steadystate analysis also carries over with probabilistic business cycles.

Two remarks are in order regarding the response of the fraction of labor at good firms to a negative demand shock. First, the initial drop in $l_{g}$ at the onset of a recession contradicts our argument in Section 2 that the scarring effect takes time to work. Our calibration exercises suggest that this feature is robust and can be understood as follows. Recessions shift both exit margins to younger ages. While the shift of the exit margin for unsure firms clears out both bad firms and good firms, the shift of the exit margin for good firms clears out only good firms, so that in total more good firms are cleared out than bad firms initially and $l_{g}$ drops at the onset of a recession. Since $l_{g}$ eventually converges to a value below the initial drop, and the initial drop in $l_{g}$ also stems

\footnotetext{
${ }^{22}$ Davis and Haltiwanger (1999) report a correlation coefficient of -0.17 of job destruction and job creation for the U.S. Manufacturing from 1947:1-1993:4.
} 

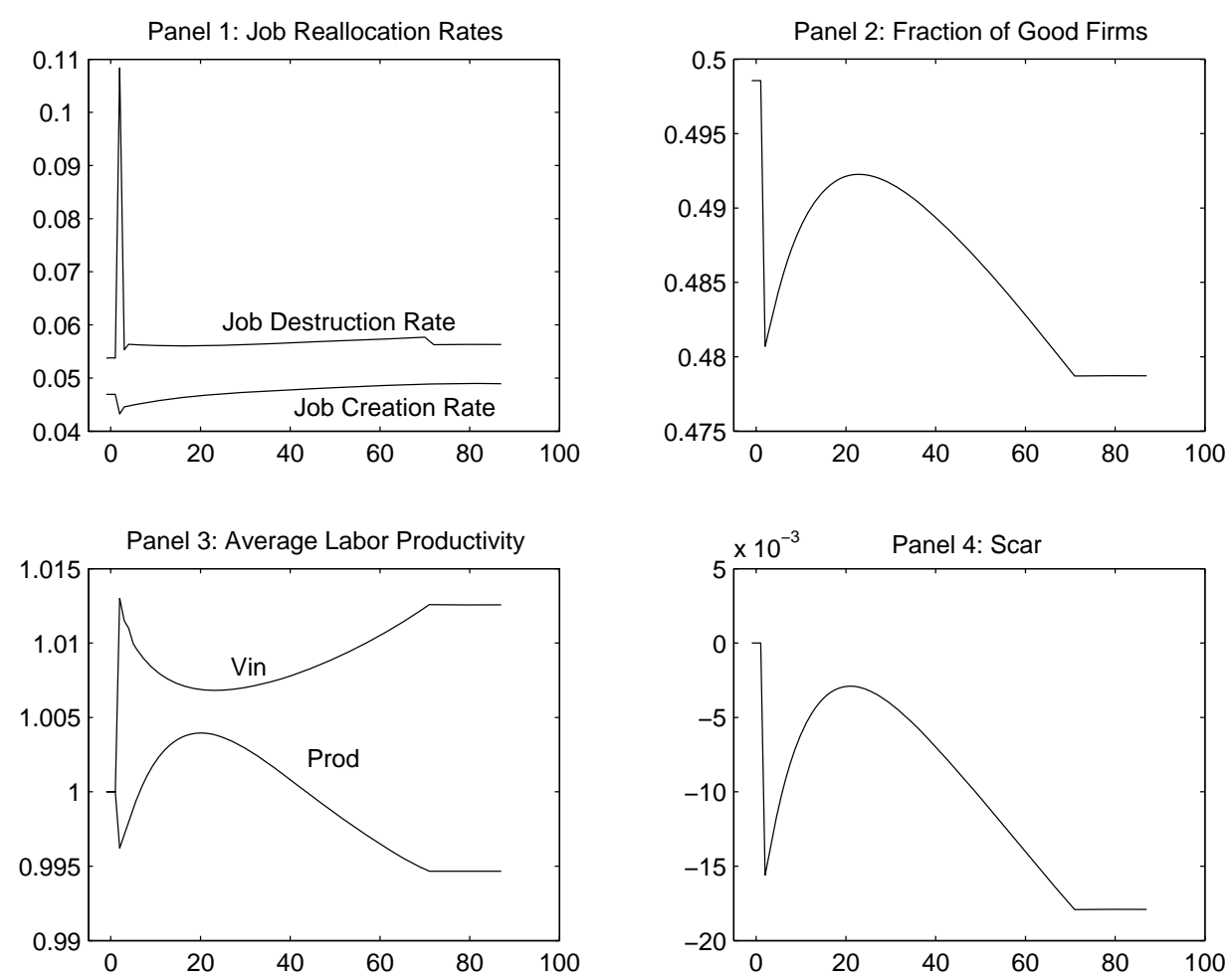

Figure 4: Response to a Negative Demand Shock: vin is the detrended average labor productivity driven only by the cleansing effect, prod is the detrended average labor productivity driven by both the cleansing effect and the scarring effect. Scar = prod-vin. The horizontal axis denotes quarters, with the quarter labeled 0 denoting the onset of a recession. 
from learning, this result does not hurt our argument that in a model with learning, recessions create a scarring effect by shifting resources toward bad firms.

Second, the response of $l_{g}$ shown in Panel 2 is hump-shaped: it drops initially, increases gradually, then declines again. This feature is mainly due to the response of the exit margins over the cycle. When a recession first strikes, the exit margins over-shift to the left, and shift back gradually as the recession persists. As the exit margin for unsure firms shifts back, more good firms are allowed to reach their potential; meanwhile, as the exit margin for good firms shifts back, no old good firms exit for several quarters. Hence, $l_{g}$ increases after the initial drop. The exit margins reach their stable points after about 20 quarters. From then on, $l_{g}$ starts to fall, with old good firms gradually being cleared out but not enough new good firms being realized. Another part of this hump-shaped response comes from the entry margin. Because they have had no time to learn, newly entered cohorts have the least efficient cross-idiosyncratic productivity firm distribution in the industry, so that entry tends to drive down $l_{g}$. When entry falls in a recession, the negative impact of entry on $l_{g}$ is also reduced, which contributes to part of the increase in $l_{g}$ after the initial drop.

To summarize, despite some transitory dynamics, Panel 1 and Panel 2 of Figure 4 suggest that both the conventional cleansing effect established in Proposition 1, and the scarring effect established in Proposition 3, carry over with probabilistic business cycles.

\subsubsection{Implications for Productivity}

Next, we turn to the quantitative implications of the model for the cyclical behavior of average labor productivity. Let $A$ represent the leading technology. With one worker per firm setup and firm-level

productivity given by $\frac{A \cdot \theta}{(1+\gamma)^{a}}$, average labor productivity is affected by $A$ and the firm distribution across $a$ and $\theta$. While technological progress drives $A$, and thus average labor productivity, to grow at a trend rate $\gamma$ (the technological pace), demand shocks add fluctuations around this trend by affecting the labor distribution across $a$ and $\theta$.

To analyze the fluctuations of average labor productivity over the cycle, we define de-trended average labor productivity as the average of $\frac{\theta}{(1+\gamma)^{a}}$ over heterogeneous firms. In evaluating this measure, recall that there are two competing effects. On the one hand, the cleansing effect drives down the average $a$ by lowering the cut-off ages for each idiosyncratic productivity, causing average labor productivity to rise. On the other hand, the scarring effect drives down the average $\theta$ by shifting resources away from good firms, causing average labor productivity to fall. To separate the two effects, we generate two indexes for average labor productivity. The first index is the average 
of $\frac{\theta}{(1+\gamma)^{a}}$ across all firms in operation, defined as the following:

$$
\operatorname{prod}=\frac{\sum_{f}\left(\frac{\theta^{e}}{(1+\gamma)^{a}}\right) \cdot f\left(\theta^{e}, a\right)}{\sum_{f} f\left(\theta^{e}, a\right)} .
$$

This measure is affected by both cleansing and scarring effects. The other index is the average of $\frac{1}{(1+\gamma)^{a}}$ across all existing firms, defined as:

$$
\operatorname{vin}=\frac{\sum_{f}\left(\frac{1}{(1+\gamma)^{a}}\right) \cdot f\left(\theta^{e}, a\right)}{\sum_{f} f\left(\theta^{e}, a\right)} \text {. }
$$

This measure is affected only by the cleansing effect. To compare the relative magnitude of these two effects, their initial levels are both normalized as 1 . Since only the cleansing effect drives the dynamics of vin but both cleansing and scarring effects drive the dynamics of prod, the gap between vin and prod reflects the magnitude of the scarring effect. A scarring index measures this gap. It is defined as:

$$
\text { scar }=\operatorname{prod}-\text { vin } .
$$

Panel 3 in Figure 4 traces the evolution of vin and prod in response to a negative demand shock. As the negative demand shock strikes, the cleansing effect alone raises the average labor productivity to 1.013 while the scarring effect brings the average labor productivity down to 0.9974 . After 70 quarters, prod converges to 0.9947 while vin converges to 1.0126 . The dynamics of the scarring index in response to a negative demand shock is plotted in Panel 4 of Figure 4. The scarring index remains negative following a negative demand shock and eventually converges to -0.0179 . This matches the predictions of our model that the scarring effect plays against the conventional cleansing effect during recessions by shifting resources away from good firms, driving down the average labor productivity.

\subsubsection{Simulation of U.S. Manufacturing Job Flows}

To gauge whether the scarring effect is likely to be relevant at business cycle frequencies, we simulate our model's response to random demand realizations generated by the model's Markov chain. We perform 1000 simulations of 87 quarters each. Results are presented in Table 2. The reported statistics are means (standard deviations) based on 1000 simulated samples. Sample statistics for U.S. Manufacturing data for the 87 quarters from the second quarter of 1972 to the fourth quarter 


\begin{tabular}{|l|c|c|}
\hline & simulation statistics & data \\
\hline$j d_{\text {mean }}$ & $5.21 \%(0.0593 \%)$ & $5.6 \%$ \\
\hline$j d_{\text {std }}$ & $1.34 \%(0.1100 \%)$ & $1.66 \%$ \\
\hline$j c_{\text {mean }}$ & $4.83 \%(0.0158 \%)$ & $5.19 \%$ \\
\hline$j c_{\text {std }}$ & $0.24 \%(0.0055 \%)$ & $0.95 \%$ \\
\hline corr $($ prod,$q)$ & $0.1221(0.2131)$ & $0.5537^{*}$ \\
\hline
\end{tabular}

Table 2: Means (std errors) of 1000 Simulated 87-quarter Samples: $j d$ is the job destruction rate, $j c$ is the job creation rate, prod is detrended average labor productivity, $q$ is detrended aggregate output. Data comes from the U.S. Manufacturing job flow series for 1972:2-1993:4, compiled by Davis and Haltiwanger. *Detrended average labor productivity is calculated as output per production worker, with output measured by industrial production index. The quarterly series of industrial production index of U.S. manufacturing sector for 1972:2-1993:4 comes from the Federal Reserve and the series of total production workers comes from the Bureau of Labor Statistics.

of 1993 are included for comparison. In the table, $j d$ and $j c$ represent the job destruction and job creation rate; $\operatorname{prod}$ and $q$ represent de-trended average labor productivity and de-trended output.

Table 2 suggests that our calibrated model can replicate the observed patterns of job flows; moreover, the positive correlation coefficient of 0.1221 between $\operatorname{prod}$ and $q$ implies that our model generates procyclical average labor productivity for the U.S. manufacturing sector in the relevant period. Put differently, under our benchmark calibration the scarring effect on cyclical productivity dominates the cleansing effect.

\subsection{Sensitivity Analysis of the Dominance of Scarring over Cleansing}

In the baseline parameterization, we follow Caballero and Hammour (1994) in setting the quarterly technological pace $\gamma$ equal to 0.007 . The value was estimated by attributing all output growth of the U.S. manufacturing sector to technological progress, which may exaggerate the technological pace in the relevant period. An alternative estimate of $\gamma$, has been provided by Basu, Fernald and Shapiro (2001), who estimate TFP growth for different industries in the U.S. from 1965 to 1996 after controlling for employment growth, factor utilization, capital adjustment costs, quality of inputs and deviations from constant returns and perfect competition. They estimate a quarterly technological pace of 0.0037 for durable manufacturing, a pace of 0.0027 for non-durable manufacturing and an even slower pace for other sectors.

How would a slow pace of technological progress affect the magnitudes of the scarring and cleansing effects? To address this question, we re-calibrate our model assuming $\gamma=0.003$, matching the same moments of job creation and destruction as before, and simulate responses to a negative demand shock. The results are presented in Table 3 together with results from the baseline 


\begin{tabular}{|l|r|r|}
\hline Calibration Results & $\gamma=\mathbf{0 . 0 0 3}$ & $\boldsymbol{\gamma}=\mathbf{0 . 0 0 7}$ \\
\hline calibrated $p$ & 0.0830 & 0.0800 \\
\hline calibrated $\varphi$ & 0.1200 & 0.1420 \\
\hline $\begin{array}{l}\text { Response to a Negative } \\
\text { Demand Shock }\end{array}$ & & \\
\hline vin (when a recession strikes) & 1.0052 & 1.0130 \\
\hline $\begin{array}{l}\text { vin (70 quarters after a reces- } \\
\text { sion strikes) }\end{array}$ & 1.0029 & 1.0126 \\
\hline prod (when a recession strikes) & 0.9866 & 0.9974 \\
\hline $\begin{array}{l}\text { prod (70 quarters after a reces- } \\
\text { sion strikes) }\end{array}$ & 0.9820 & 0.9947 \\
\hline scar (when a recession strikes) & -0.0186 & -0.0156 \\
\hline $\begin{array}{l}\text { scar (70 quarters after a reces- } \\
\text { sion strikes) }\end{array}$ & -0.0209 & -0.0179 \\
\hline
\end{tabular}

Table 3: Sensitivity Analysis to a Slower Technological Pace (I): prod is detrended average labor productivity, driven by both the cleansing and the scarring effects, vin is the component of detrended average labor productivity driven only by the cleansing effect, scar $=$ prod - vin. Other parameter values are as shown in Table 2 .

parameterization.

The calibration results in Table 3 suggest that the model with $\gamma=0.003$ needs a faster learning pace $(p=0.083$ compared to 0.08$)$ and a smaller prior probability of firms' being good $(\varphi=0.120$ compared to 0.142 ) to match the observed moments of job flows. ${ }^{23}$ The simulated responses suggest that slower technological progress magnifies the scarring effect, weakens the cleansing effect, and magnifies the procyclical behavior of productivity.

This result can be explained as follows. First, slower technological progress implies that the force of creative destruction is weak. A lower $\gamma$ weakens the technical disadvantage of old firms and allows both good firms and unsure firms to live longer, so that less job destruction occurs at the exit margins. A lower $\gamma$ also implies a smaller cleansing effect on average labor productivity. A recession clears out marginal firms by shifting the exit margins toward younger ages. The size of the shift is pinned down in our calibration exercises by matching $j d_{\max } \approx 11.6 \%$. Given the shift of exit margins, a slower technological pace shrinks the productivity difference between the

\footnotetext{
${ }^{23}$ Consider (8), the expression of $j d^{s s}$ for intuition. My calibration exercises look for parameter values that satisfy three moment conditions on job flows, one of which is that $j d^{s s} \approx 5.6 \%$. Proposition 3 establishes that $j d^{s s}$ decreases with the exit ages $\left(\overline{a_{g}}\right.$ and $\left.\overline{a_{u}}\right)$. It can be further shown that it increases in $p$ but decreases in $\varphi$. A slower technological pace weakens the technical disadvantage of old firms and extends their life span so that both $\overline{a_{g}}$ and $\overline{a_{u}}$ tend to increase. Hence, the job destruction rate would decrease if $p$ and $\varphi$ remain the same. A faster learning pace and a lower prior probability of being good are thus needed to match the observed mean job destruction. Thus, the paramerization of my model with $\gamma=0.003$ suggests that more job destruction comes from learning rather than creative destruction.
} 


\begin{tabular}{|l|l|l|c|}
\hline & $\begin{array}{l}\text { simulation statistics } \\
\text { with } \gamma=\mathbf{0 . 0 0 3}\end{array}$ & $\begin{array}{l}\text { simulation statistics } \\
\text { with } \gamma=\mathbf{0 . 0 0 7}\end{array}$ & data \\
\hline$j d_{\text {mean }}$ & $5.60 \%(0.0534 \%)$ & $5.21 \%(0.0593 \%)$ & $5.6 \%$ \\
\hline$j d_{\text {std }}$ & $1.23 \%(0.0996 \%)$ & $1.34 \%(0.1100 \%)$ & $1.66 \%$ \\
\hline$j c_{\text {mean }}$ & $5.25 \%(0.0171 \%)$ & $4.83 \%(0.0158 \%)$ & $5.19 \%$ \\
\hline$j c_{\text {std }}$ & $0.26 \%(0.0059 \%)$ & $0.24 \%(0.0055 \%)$ & $0.95 \%$ \\
\hline corr $($ prod,$q)$ & $0.6563(0.1599)$ & $0.1221(0.2131)$ & 0.5537 \\
\hline
\end{tabular}

Table 4: Sensitivity to A Slower Technological Pace (II): Means (std errors) of 1000 Simulated 87-quarter Samples. Definitions, measures and data sources are the same as Table 4.

vintages that have been killed and the ones that have survived, so that the impact of the cleansing effect on average labor productivity declines.

Second, when we assume a lower $\gamma$, we must also assume a higher $p$ and a lower $\varphi$ to match the moments of job destruction. This re-calibration implies a larger role for learning in job destruction: firms not only learn faster, but are more likely to learn that they are bad. This also gives a larger scarring effect on average labor productivity: a faster learning pace implies a higher opportunity cost of not allowing unsure firms to survive; a smaller prior probability of being good suggests that learning has a greater marginal impact on cross-section efficiency.

Table 4 reports the simulation statistics of 1000 simulated 87-quarter samples when $\gamma=0.003$. Results when $\gamma=0.007$ and sample statistics from data are included for comparison. Our model with $\gamma=0.003$ generates a correlation coefficient of 0.4819 between detrended average labor productivity and detrended output. Productivity is strongly procyclical, almost as much as in the data.

\section{Conclusion}

How do recessions affect resource allocation? This paper suggests that firm learning has important consequences for this question. We posit that, in addition to the cleansing effect proposed by previous authors, recessions create a scarring effect by interrupting the learning process. Recessions kill off potentially good firms, truncate the learning process that reallocates resources into good firms, and exacerbate the allocative inefficiency in an industry. The empirical relevance of the scarring effect is examined in Section 4. Using data on U.S. manufacturing job flows, we find that the scarring effect dominates the cleansing effect in the U.S. manufacturing sector from 1972 to 1993, and can account for the observed degree of procyclical productivity.

Firm size can be introduced to the current model without modifying the basic results. If firms are allowed to choose their employment levels, both vintage and expected idiosyncratic productivity 
would affect a firm's size positively: holding belief constant, younger firms hire more labor; holding vintage constant, good firms are bigger. This modification will not change our results qualitatively or quantitatively. ${ }^{24}$ Rather, it gives rise to some interesting new predictions. With good firms bigger than unsure firms, a firm would increase its employment once it learns itself as good, so that an additional job creation margin arises from learning. Then the exit of potentially good firms during recessions would also reduce later job creation driven by learning. This is consistent with the argument by Caballero and Hammour (2004) that spikes in job destruction during recessions in the US manufacturing sector are usually followed by sluggish job creation during the recovery phase of the cyclical downturn.

Finally, the empirical relevance of the scarring effect remains to be explored in a wider framework. Our calibration exercises have focused on the U.S. manufacturing sector from 1972 to 1993, where job destruction is documented more responsive to business cycles than job creation. However, Foote (1997) documents that in services, fire, transportation and communications, retail trade, and wholesale trade, job creation is more volatile than job destruction. Moreover, Hall (2005) suggests that the recession of 2001 is dominated by sluggish creation rather than increased destruction. Notice that, in Caballero and Hammour (1994) and in our model, the creation margin and the destruction margin accommodate demand variations together. More responsive creation can be generated with entry cost adjusted less sensible to entry size. The question then becomes, would relatively more responsive job creation hurt the dominance of the scarring effect? It could, since recessions leave "scars" by killing off potentially good firms on the destruction side. It may not, because a larger decline in job creation also introduces fewer potentially good firms on the creation side. Whether "scarring" dominates "cleansing" in sectors other than manufacturing, or in a recession characterized by sluggish creation, remains an interesting question.

\footnotetext{
${ }^{24}$ This is an earlier version of the model. Allowing for firm size does not change my results qualitatively. As seen in Figure 3, as long as recessions reduce price, the exit margins will shift to younger ages, so that there is a cleansing effect with younger average vintage, and a scarring effect with good firms in the shaded area disappearing. These happen regardless of firm size. Neither will the quantitative results be affected. With bigger good firms, the industrial proportion of labor at good firms is generally higher than the one in the current model, so that the decline in this proportion brought by recessions (the scarring effect) has a smaller marginal effect on productivity. However, the average per-labor vintage would also be higher since firms with better vintages are bigger, so that the increase in average vintage brought by recessions (the cleansing effect) also has a smaller marginal effect on productivity. It turns out that the scarring effect still dominates the cleansing effect in the calibration exercises. The version of the model with firms differing in size is available upon request.
} 


\section{Appendix}

\subsection{Approximating Value Functions with Krusell \& Smith (1998) Approach}

The key computational task is to map $F$, the firm distribution across ages and idiosyncratic productivity, given demand level $D$, into a set of value functions $V\left(\theta^{e}, a ; F, D\right)$. To make the state space tractable, we define a variable $X$ such that:

$$
X(F)=\sum_{a} \sum_{\theta^{e}}(1+\gamma)^{-a} \cdot \theta^{e} \cdot f\left(\theta^{e}, a\right) .
$$

Combining (9) with (6) and (7), we get

$$
P(F, D) \cdot A=\frac{D}{X\left(F^{\prime}\right)}
$$

$A$ is the leading technology; $F^{\prime}$ is the updated firm distribution after entry and exit; $X^{\prime}$ corresponds to $F^{\prime} ; P(F, D)$ is the equilibrium price in a period with initial aggregate state $(F, D)$. Since $F^{\prime}=H(F, D)$, the above equation can be re-written as

$$
P(F, D) \cdot A=\frac{D}{X(H(F, D))}
$$

Given these definitions, the single-period profitability of a firm of idiosyncratic productivity $\theta^{e}$ and age $a$, given aggregate state $(F, D)$, equals

$$
\pi(a, \theta ; F, D)=\frac{D}{X(H(F, D))} \cdot(1+\gamma)^{-a} \cdot(\theta+\varepsilon)-1
$$

Thus, the aggregate state $(F, D)$ and its law of motion help firms to predict future profitability by suggesting sequences of $X$ 's from today onward under different paths of demand realizations. The question then is: what is the firm's critical level of knowledge of $F$ that allows it to predict the sequence of $X^{\prime} s$ over time? Although firms would ideally have full information about $F$, this is not computationally feasible. Therefore we need to find an information set $\Omega$ that delivers a good approximation of firms' equilibrium behavior, yet is small enough to reduce the computational difficulty.

I look for an $\Omega$ through the following procedure. In step 1 , we choose a candidate $\Omega$. In step 2 , we postulate perceived laws of motion for all members of $\Omega$, denoted $H_{\Omega}$, such that $\Omega^{\prime}=H_{\Omega}(\Omega, D)$. In step 3, given $H_{\Omega}$, we calculate firms' value functions on a grid of points in the state space of $\Omega$ applying value function iteration, and obtain the corresponding industry-level decision rules - entry sizes and exit ages across aggregate states. In step 4, given such decision rules and an initial firm distribution. We simulate the behavior of a continuum of firms along a random path of demand realizations, and derive the implied aggregate behavior - a time series of $\Omega$. In step 5, we use the stationary region of the simulated series to estimate the implied laws of motion and compare them with the perceived $H_{\Omega}$; if different, we update $H_{\Omega}$, return to step 3 and continue until convergence. In step 6 , once $H_{\Omega}$ converges, we evaluate the fit of $H_{\Omega}$ in terms of tracking the aggregate behavior. 


\begin{tabular}{|c|c|}
\hline$\Omega$ & $\{X\}$ \\
\hline$H_{\Omega}$ & $\begin{array}{l}H_{x}\left(X, D_{h}\right): \log X^{\prime}=1.2669+0.8532 \log X \\
H_{x}\left(X, D_{l}\right): \log X^{\prime}=2.4234+0.7175 \log X\end{array}$ \\
\hline$R^{2}$ & $\begin{array}{l}\text { for } D_{h}: 0.9837 \\
\text { for } D_{l}: 0.8062\end{array}$ \\
\hline standard forecast error & $\begin{array}{l}\text { for } D_{h}: 0.0000036073 \% \\
\text { for } D_{l}: 0.000030068 \%\end{array}$ \\
\hline maximum forecast error & $\begin{array}{l}\text { for } D_{h}: 0.000049895 \% \\
\text { for } D_{l}: 0.00074675 \%\end{array}$ \\
\hline $\begin{array}{l}\text { Den Haan \& Marcet test sta- } \\
\text { tistic }\left(\chi_{7}^{2}\right)\end{array}$ & 0.8007 \\
\hline
\end{tabular}

Table 5: The Estimated Laws of Motion and Measures of Fit

If the fit is satisfactory, we stop; if not, we return to step 1, make firms more knowledgeable by expanding $\Omega$, and repeat the procedure.

I start with $\Omega=\{X\}$ - firms observe $X$ instead of $F$. We further assume that firms perceive the sequence of future coming $X^{\prime} s$ as depending on nothing more than the current observed $X$ and the state of demand. The perceived law of motion for $X$ is denoted $H_{x}$ so that $X^{\prime}=H_{x}(X, D)$. We then apply the procedure described above and simulate the behavior of a continuum of firms over 5000 periods. The results are presented in Table 5 .

As shown in Table 5, the estimated $H_{x}$ is log-linear. The fit of $H_{x}$ is quite good, as suggested by the high $R^{2}$, the low standard forecast error, and the low maximum forecast error. The good fit when $\Omega=\{X\}$ implies that firms perceiving these simple laws of motion make only small mistakes in forecasting future prices. To explore the extent to which the forecast error can be explained by variables other than $X$, we implement the Den Haan and Marcet (1994) test using instruments $\left[1, X, \mu_{a}, \sigma_{a}, \gamma_{a}, \kappa_{a}, r_{u}\right]$, where $\mu_{a}, \sigma_{a}, \gamma_{a}, \kappa_{a}, r_{u}$ are the mean, standard deviation, skewness, and kurtosis of the age distribution of firms, and the fraction of unsure firms, respectively. The test statistic is 0.8007 , well below the critical value at the $1 \%$ level. This suggests that given the estimated laws of motion, we do not find much additional forecasting power contained in other variables. Nevertheless, we expand $\Omega$ further to include $\sigma_{a}$, the standard deviation of the age distribution of firms. The results when $\Omega=\left\{X, \sigma_{a}\right\}$ are shown in Table 6 .

Apparently, the measures of fit do not change much. Furthermore, the impact of changes in $\sigma_{a}$ on the approximated value function is very small (less than $0.5 \%$ ). This confirms that the inclusion of information other than $X$ improves the forecast accuracy by only a very small amount.

Figure 5 displays the value of staying for heterogeneous firms as a function of $a, \theta^{e}, D$ and $X(\log X)$. Figure 6 displays the corresponding optimal exit ages and entry sizes. These tables and figures suggest that our solution using $X$ to approximate the aggregate state closely replicates optimal firm behavior at the equilibrium. These results were robust when we experimented with different parameterization of the model. Therefore, we use the solution based on $\Omega=\{X\}$ to generate all the relevant series. 


\begin{tabular}{|c|c|}
\hline$\Omega$ & $\left\{X, \sigma_{a}\right\}$ \\
\hline$H_{\Omega}$ & $\begin{array}{l}\text { booms }(\log X) \text { : } \\
\log X^{\prime}=0.1261+0.9653 \log X+0.3246 \sigma_{a} \\
\text { recessions }(\log X): \\
\sigma_{a}^{\prime}=0.0079+0.0076 \log X+0.8988 \sigma_{a} \\
\text { booms }\left(\sigma_{a}\right): \\
\log X^{\prime}=-0.1485+0.9291 \log X+1.0317 \sigma_{a} \\
\text { recessions }\left(\sigma_{a}\right): \\
\quad \sigma_{a}^{\prime}=0.0789+0.0166 \log X+0.6924 \sigma_{a}\end{array}$ \\
\hline$R^{2}$ & $\begin{array}{l}\text { booms }(\log X): 0.9940 \\
\text { recessions }(\log X): 0.9287 \\
\text { booms }\left(\sigma_{a}\right): 0.9571 \\
\text { recessions }\left(\sigma_{a}\right): 0.5812\end{array}$ \\
\hline $\begin{array}{l}\text { standard forecast } \\
\text { error }\end{array}$ & $\begin{array}{l}\text { booms }(\log X): 0.0000069741 \% \\
\text { recessions }(\log X): 0.000068307 \% \\
\text { booms }\left(\sigma_{a}\right): 0.00012513 \% \\
\text { recessions }\left(\sigma_{a}\right): 0.00097406 \%\end{array}$ \\
\hline $\begin{array}{l}\text { maximum forecast } \\
\text { error }\end{array}$ & $\begin{array}{l}\text { booms }(\log X): 0.000087730 \% \\
\text { recessions }(\log X): 0.0016626 \% \\
\text { booms }\left(\sigma_{a}\right): 0.0014396 \% \\
\text { recessions }\left(\sigma_{a}\right): 0.028074 \%\end{array}$ \\
\hline $\begin{array}{l}\text { Den Haan \& } \quad \text { } \\
\text { Marcet test statis- } \\
\text { tic }\left(\chi_{7}^{2}\right)\end{array}$ & 0.9216 \\
\hline
\end{tabular}

Table 6: The Estimated Laws of Motion with two moments and Measures of Fit 

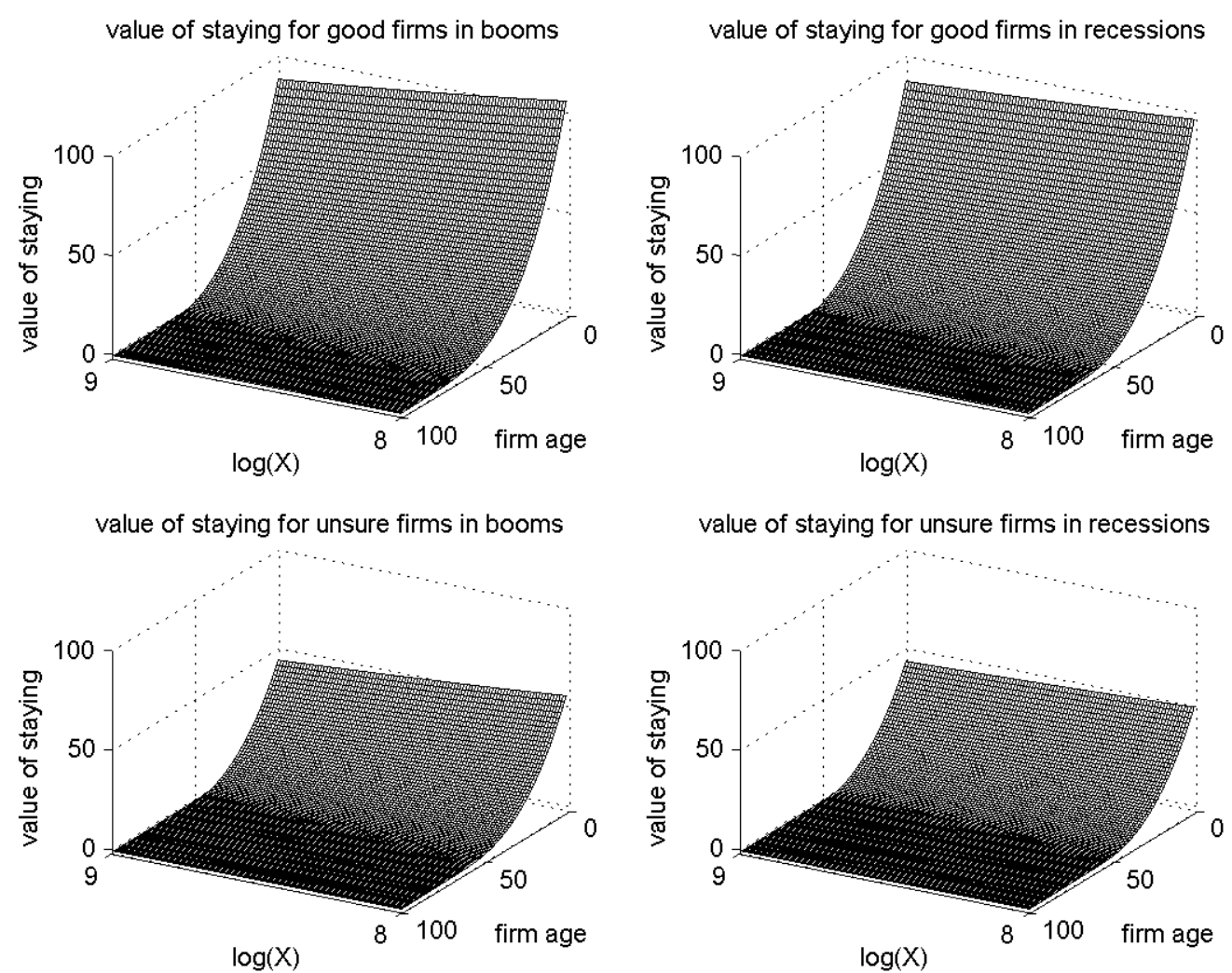

Figure 5: Expected Value of Staying: aggregate state variables are $D$ and $\log X$ (the $\log$ of detrended output), firm-level state variables are firm age and belief (good or unsure); the parameter choices underlying these figures are summarized in Table 1 . 

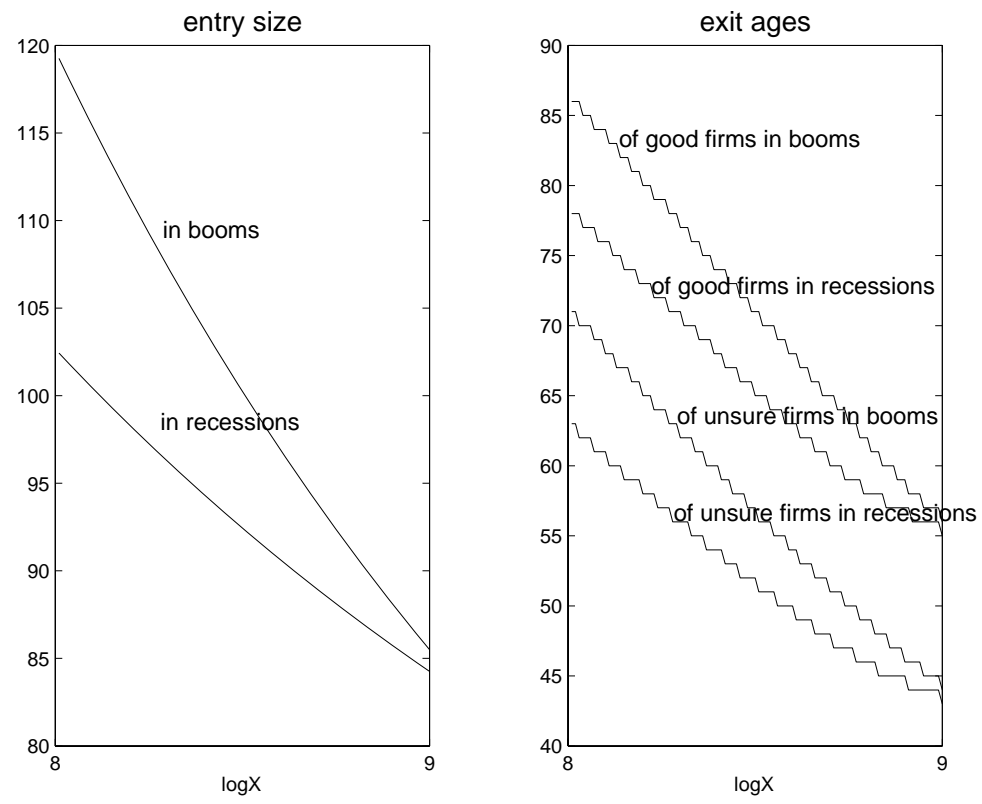

Figure 6: Industry-level Policy Functions: Entry Size and Exit Ages. Aggregate states are $D$ (booms or recessions) and $\log X$ (the $\log$ of detrended output).

\subsection{Proof of Proposition 1}

Proof. According to the condition of competitive pricing and the definition of a steady state,

$$
D=P_{t} A_{t} \cdot\left\{\sum_{a=0}^{\overline{a_{u}}}\left[\theta_{u} f\left(\theta_{u}, a\right)(1+\gamma)^{-a}\right]+\sum_{a=0}^{\overline{a_{g}}}\left[\theta_{g} f\left(\theta_{g}, a\right)(1+\gamma)^{-a}\right]\right\}
$$

with $D$ as the time-invariant demand, $f\left(\theta^{e}, a\right)$ the time-invariant number of firms with $\left(\theta^{e}, a\right)$, and $\overline{a_{g}}, \bar{a}_{u}$ the time-invariant exit ages for good and unsure firms. It suggests that $P_{t} A_{t}$ must also be time-invariant. We let $P_{t} A_{t}=P A$.

$f(0)$ represents the time-invariant entry size at the steady state. Let $V\left(\theta^{e}, a\right)$ be the timeinvariant expected value of staying of a firm with belief $\theta^{e}$ and age $a$. The exit condition for good firms, $V\left(\theta_{g}, \overline{a_{g}}\right)=0$, suggests:

$$
\theta_{g} P A(1+\gamma)^{-\overline{a_{g}}}-1=0
$$

With $f\left(\theta^{e}, a\right)$ given by all-or-nothing learning, (10) and (11) together with the steady-state struc- 
ture as shown in Figure 2, imply

$$
f(0) \cdot \frac{(1+\gamma)^{\bar{a}_{g}}}{\theta_{g}}\left[\begin{array}{c}
\left(\theta_{u}-\varphi \theta_{g}\right) \sum_{a=0}^{\bar{a}_{u}}\left(\frac{1-p}{1+\gamma}\right)^{a}+\varphi \theta_{g} \sum_{a=0}^{\bar{a}_{g}}\left(\frac{1}{1+\gamma}\right)^{a}+ \\
\varphi \theta_{g}(1-p)^{\bar{a}_{u}+1} \\
\sum_{a=\bar{a}_{u}+1}^{\bar{a}_{g}}\left(\frac{1}{1+\gamma}\right)^{a}
\end{array}\right]=D .
$$

The free entry condition, $V\left(\theta_{u}, 0\right)=C(f(0))$, suggests

$$
\sum_{a=0}^{\bar{a}_{u}} \beta^{a}\left[\frac{P A \theta_{u}}{(1+\gamma)^{a}}-1\right] \lambda\left(\theta_{u}, a\right)+\sum_{a=0}^{\bar{a}_{g}} \beta^{a}\left[\frac{P A \theta_{g}}{(1+\gamma)^{a}}-1\right] \lambda\left(\theta_{g}, a\right)=C(f(0)) .
$$

$\lambda\left(\theta_{u}, a\right)$ and $\lambda\left(\theta_{g}, a\right)$ are the probabilities of staying in operation at age $a$ as an unsure firm and a good firm, and are given by the all-or-nothing learning.

The exit condition for unsure firms, $V\left(\theta_{u}, \overline{a_{u}}\right)=0$, suggests:

$$
\theta_{u} P A(1+\gamma)^{-\overline{a_{u}}}-1+\beta p \varphi \sum_{a=\overline{a_{u}}+1}^{\overline{a_{g}}} \beta^{a-\overline{a_{u}}-1}\left[\theta_{g} P A(1+\gamma)^{-a}-1\right]=0
$$

Combining (11) and (14) gives

$$
\left(\frac{\theta_{u}}{\theta_{g}}+\frac{p \varphi \beta}{1+\gamma-\beta}\right)(1+\gamma)^{\bar{a}_{g}-\bar{a}_{u}}=1+\frac{p \varphi \beta}{1-\beta}-\frac{p \varphi \beta \gamma}{(1-\beta)(1+\gamma-\beta)} \beta^{\bar{a}_{g}-\bar{a}_{u}} .
$$

(15) solves $\bar{a}_{g}-\bar{a}_{u}$. To establish the existence and the uniqueness of the solution, let $F\left(\bar{a}_{g}-\bar{a}_{u}\right)$ represents the left-hand side, and $G\left(\bar{a}_{g}-\bar{a}_{u}\right)$ the right-hand side of (15). It can be shown that $G^{\prime}>0$ but $G^{\prime \prime}<0, F^{\prime}>0$ and $F^{\prime \prime}>0$; moreover,

$$
F(0)<G(0) \text { as long as } \frac{\theta_{u}}{\theta_{g}}<1
$$

Since $\theta_{u}<\theta_{g}$ holds by definition, $F$ and $G$ must cross once at a positive value of $\bar{a}_{g}-\bar{a}_{u}$, as shown 
in the following figure

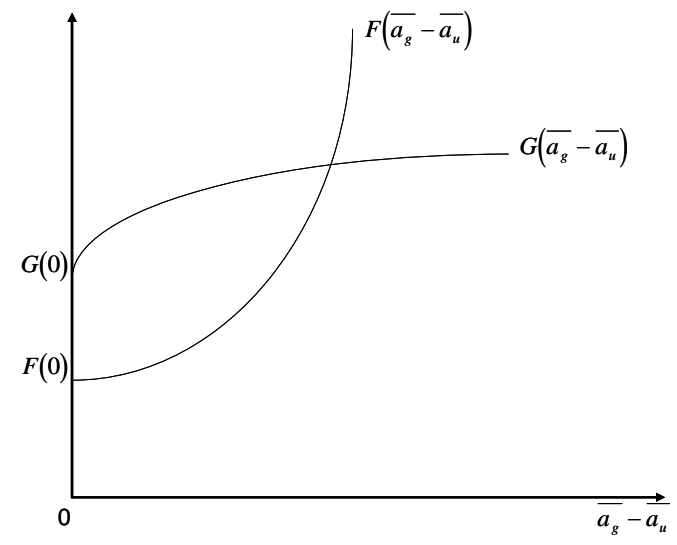

Hence, (15) determines a unique value for $\bar{a}_{g}-\bar{a}_{u}$. With the value of $\bar{a}_{u}=\bar{a}_{g}-\left(\bar{a}_{g}-\bar{a}_{u}\right)$ plugged in, (12) and (13) jointly determine $f(0)$ and $\bar{a}_{g}$ when $C^{\prime}>0$.

Notice that with entry cost independent of entry size, $C^{\prime}=0$. (15), (12) and (13) become recursive. (15) determines $\bar{a}_{g}-\bar{a}_{u}$. With $\bar{a}_{u}=\bar{a}_{g}-\left(\bar{a}_{g}-\bar{a}_{u}\right)$, (13) determines $\bar{a}_{g}$. Then (12) determines $f(0)$. Since $D$ is only present in (12), variations in $D$ would be exclusively accommodated by variations in $f(0)$.

\subsection{Proof of Proposition 2:}

Proof. combining (12) with (13) and replacing $\bar{a}_{u}$ by $\bar{a}_{g}-\left(\bar{a}_{g}-\bar{a}_{u}\right)$ gives

$$
\begin{aligned}
& \frac{(1+\gamma)^{\bar{a}_{g}}}{\theta_{g}}\left[\begin{array}{c}
\left(\theta_{u}-\varphi \theta_{g}\right) \sum_{a=1}^{\bar{a}_{u}}\left(\frac{1-p}{1+\gamma}\right)^{a}+\varphi \theta_{g} \sum_{a=1}^{\bar{a}_{g}}\left(\frac{1}{1+\gamma}\right)^{a}+ \\
\varphi \theta_{g}(1-p)^{\bar{a}_{u}+1} \sum_{a=\bar{a}_{u}+1}^{\bar{a}_{g}}\left(\frac{1}{1+\gamma}\right)^{a}
\end{array}\right] . \\
& c^{-1}\left\{\frac{(1+\gamma)^{\bar{a}_{g}}}{\theta_{g}}\left\{\begin{array}{c}
\sum_{a=1}^{\bar{a}_{u}} \beta^{a}\left[\begin{array}{c}
(1-p)^{a}\left(\frac{\theta_{u}}{(1+\gamma)^{a}}-1\right)+ \\
\varphi\left(1-(1-p)^{a}\right)\left(\frac{\theta_{g}}{(1+\gamma)^{a}}-1\right)
\end{array}\right]+ \\
\varphi\left(1-(1-p)^{\left.\bar{a}_{u}+1\right)} \sum_{\substack{\bar{a}_{g} \\
\hat{a}_{u}-1}}^{\beta^{a}\left(\frac{\theta_{g}}{(1+\gamma)^{a}}-1\right)+}\right.
\end{array}\right\}\right) \\
& =D
\end{aligned}
$$

The left-hand monotonically increases in $\bar{a}_{g}$. Hence, $\frac{d\left(\bar{a}_{g}\right)}{d D} \geq 0$. With $\bar{a}_{g}-\bar{a}_{u}$ independent of $D$ as suggested by (8), $\frac{d\left(\bar{a}_{u}\right)}{d D}=\frac{d\left(\bar{a}_{g}-\left(\bar{a}_{g}-\bar{a}_{u}\right)\right)}{d D} \geq 0$.

Similarly, with $\bar{a}_{g}-\bar{a}_{u}$ independent of $D, \frac{d\left(j d^{s s}\right)}{d D}=\frac{d\left(j d^{s s}\right)}{d \bar{a}_{u}} \cdot \frac{d \bar{a}_{u}}{d D} \leq 0$. 


\subsection{Proof of Proposition 3:}

Proof. (15) implies that $\bar{a}_{g}-\overline{a_{u}}$ is independent of $D$, so that

$$
\frac{d\left(r_{g}\right)}{d(D)}=\frac{d\left(r_{g}\right)}{d\left(\overline{a_{u}}\right)} \cdot \frac{d\left(\overline{a_{u}}\right)}{d(D)}
$$

Proposition 3 has established that $\frac{d\left(\overline{a_{u}}\right)}{d(D)} \geq 0$. Therefore, $\frac{d\left(r_{g}\right)}{d(D)} \geq 0$ if and only if $\frac{d\left(r_{g}\right)}{d\left(\overline{a_{u}}\right)} \geq 0$.

With $\frac{\overline{a_{u}}}{1-(1-p)^{\overline{a_{u}}}}=x, \frac{d\left(r_{g}\right)}{d\left(\overline{a_{u}}\right)}=\frac{d\left(r_{g}\right)}{d(x)} \cdot \frac{d(x)}{d\left(\overline{a_{u}}\right)}$. Since $\frac{d\left(r_{g}\right)}{d(x)}>0, \frac{d\left(r_{g}\right)}{d\left(\overline{a_{u}}\right)} \geq 0$ if and only if $\frac{d(x)}{d\left(\overline{a_{u}}\right)} \geq 0$.

Hence, we need to prove that $\frac{d(x)}{d\left(\overline{a_{u}}\right)} \geq 0$.

$1-(1-p)^{\overline{a_{u}}}$ is plotted in the following graph as a function of $\overline{a_{u}}$. Since

$$
\frac{d\left(1-(1-p)^{\overline{a_{u}}}\right)}{d\left(\overline{a_{u}}\right)}=-(1-p)^{\overline{a_{u}}} \cdot \ln (1-p)>0
$$

but

$$
\frac{d^{2}\left(1-(1-p)^{\overline{a_{u}}}\right)}{d\left(\overline{a_{u}}\right)^{2}}=-(1-p)^{\overline{a_{u}}} \cdot(\ln (1-p))^{2}<0
$$

the curve is concave.

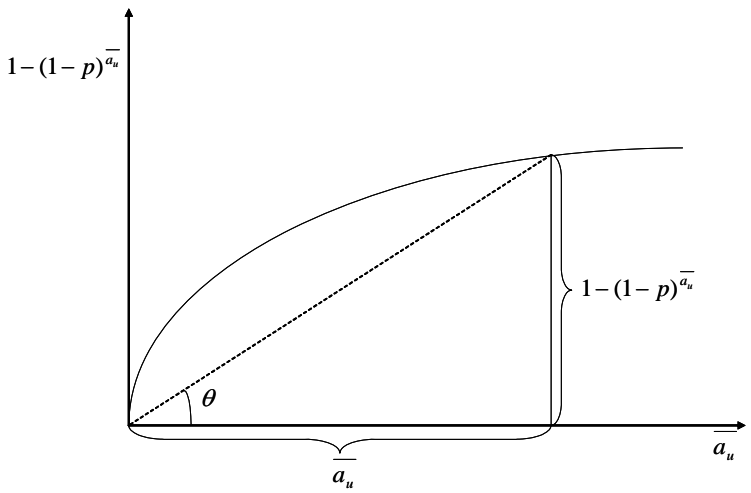

Clearly, it indicates that $x=\frac{\overline{a_{u}}}{1-(1-p)^{\overline{a_{u}}}}=\cot (\theta)$. The concavity of the curve suggests that as $\overline{a_{u}}$ increases, the angle of $\theta$ shrinks and $\cot (\theta)$ increases. Therefore, $x$ increases in $\overline{a_{u}}$. 


\section{REFERENCES}

Aghion, Philippe and Howitt, Peter. "Growth and Unemployment." Review of Economic Studies, July 1994, 61(3), pp. 477-494.

Aghion, Philippe and Saint-Paul, Gilles. "Virtues of Bad Times." Macroeconomic Dynamics, September 1998, 2(3), pp. 322-44.

Aruoba, S. Boragan; Rubio-Ramirez, Juan F. and Fernandez-Villaverde, Jesus. "Comparing Solution Methods for Dynamic Equilibrium Economies." Working Paper 2003-27, Federal Reserve Bank of Atlanta, 2003.

Aw, Bee Yan; Chen, Xiaomin and Roberts, Mark J. "Firm-level Evidence on Productivity Differentials, Turnover, and Exports in Taiwanese Manufacturing." Journal of Development Economics, October 2001, 66(1), pp. 51-86.

Baily, Martin Neil; Bartelsman, Eric J. and Haltiwanger, John. "Labor Productivity: Structural Change and Cyclical Dynamics." Review of Economics and Statistics, August 2001, 83(3), pp. $420-433$.

Baldwin, John R. The Dynamics of Industrial Competition. Cambridge University Press, 1995.

Barlevy, Gadi. "The Sullying Effect of Recessions." Review of Economic Studies, January 2002, 69(1), p65-96.

Basu, Sustanto. "Procyclical Productivity: Increasing Returns or Cyclical Utilization?" Quarterly Journal of Economics, August 1996, 111(3), pp. 719-51.

Basu, Susanto and Fernald, John G. "Aggregate productivity and aggregate technology," European Economic Review, Elsevier, 2002, vol. 46(6), pages 963-991.

Basu, Susanto; Fernald, John G. and Shapiro, Matthew D. "Productivity Growth in the 1990s: Technology, Utilization, or Adjustment?" NBER Working paper 8359, 2001.

Basu, Susanto and Miles S. Kimball, "Cyclical Productivity with Unobserved Input Variation," NBER Working Papers 5915, 1997, National Bureau of Economic Research, Inc.

Bowlus, Audra J. "Job Match Quality over the Business Cycle." Panel Data and Labour Market Dynamics, Amsterdam: North Holland, 1993, pp. 21-41.

Brsnahan, Timothy F. and Raff, Daniel M.G. "Intra-industry Heterogeneity and the Great Depression: the American Motor Vehicles Industry, 1929-1935." Journal of Economic History, June 1991, 51(2), pp. 317-31.

Caballero, Ricardo J. and Hammour, Mohamad L. "The Cleansing Effect of Recessions." American Economic Review, December 1994, 84(5), pp. 1350-68. 
Caballero, Ricardo J. and Hammour, Mohamad L. "On the timing and Efficiency of Creative Destruction." Quarterly Journal of Economics, August 1996, 111(3), pp. 805-52.

Caballero, Ricardo J. and Hammour, Mohamad L. "The Cost of Recessions Revisited: a ReverseLiquidationist View." Review of Economic Studies, Vol. 72, No. 2, pp. 313-341, April 2005.

Campbell, Jeffrey R. and Fisher, Jonas D.M. "Technology Choice and Employment Dynamics at Young and Old Plants." Working Paper Series-98-24, Federal Reserve Bank of Chicago, 1998.

Campbell, Jeffrey R. and Fisher, Jonas D.M. "Aggregate Employment Fluctuations with Microeconomic Asymmetries," American Economic Review, Volume 90, Number 5, December 2000. pp. $1323-1345$

Campbell, Jeffrey R. and Fisher, Jonas D.M. "Idiosyncratic Risk and Aggregate Employment Dynamics." Review of Economic Dynamics, 2004.

Carlyle, Thomas. Critical and Miscellaneous Essays. New York, 1904, vol. 4, pp. 368-369.

Cooley, Thomas and Prescott, Edward. "Economic Growth and Business Cycles" (pp. 1-38), in Thomas Cooley, (Ed.), Frontiers of Business Cycle Research, Princeton, Princeton University Press, 1994.

Cooper, Russell; Haltiwanger, John; and Power, Laura. "Machine Replacement and Business Cycles: Lumps and Dumps." American Economic Review, 1999.

Davis, Steven J. and Haltiwanger, John. "Gross Job Flows." Handbook of Labor Economics, Amsterdam: North-Holland, 1999.

Davis, Steven J.; Haltiwanger, John and Schuh, Scott. Job Creation and Job Destruction, Cambridge, MIT Press,1996.

Davis, Steven J. and Haltiwanger, John. "Gross Job Creation, Gross Job Destruction, and Employment Reallocation." Quarterly Journal of Economics, August 1992, 107(3), pp. 818-63.

Den Haan, Wouter J. and Marcet, Albert. "Accuracy in Simulations." Review of Economic Studies, 1994, 61, pp. 3-18.

Dickens, William T. "The Productivity Crisis: Secular or Cyclical?" Economic Letters, 1982, 9(1), pp. $37-42$.

Dunne, Timothy; Roberts, Mark J. and Samuelson, Larry. "The Growth and Failure of U.S. Manufacturing Plants." Quarterly Journal of Economics, November 1989, 104(4), pp. 67198.

Ericson, Richard and Pakes, Ariel. "Markov-Perfect Industry Dynamics: A Framework for Empirical Work." Review of Economic Studies, January 1995, 62(1), pp. 53-82.

Foote, Christopher L. "Trend Employment Growth and the Bunching of firm Creation and Destruction." Quarterly Journal of Economics. August 1998, 113(3), pp. 809-834. 
Foster, Lucia; Haltiwanger, John and Krizan, C. J. "The Link Between Aggregate and Micro Productivity Growth: Evidence from Retail Trade.” NBER working paper 9120, 2002.

Foster, Lucia; Haltiwanger, John and Syverson, C. "Reallocation, Firm Turnover, and Efficiency: Selection on Productivity or Profitability?" NBER Working Papers Series no. 11555; Cambridge: National Bureau of Economic Research, 2005.

Gomes, Joao, Jeremy Greenwood, and Sergio Rebelo. "Equilibrium Unemployment." Journal of Monetary Economics, August 2001, 48(1), pp. 109-52.

Goolsbee, Austan. "Investment Tax Incentives, Prices, and the Supply of Capital Goods." Quarterly Journal of Economics, February 1998, 113(1), pp. 121-148.

Hall, Robert E. "Labor Demand, Labor Supply, and Employment Volatility." in Olivier J. Blanchard and Stanley Fischer, NBER Macroeconomics Annual. Cambridge, MA: MIT Press, 1991.

Hall, Robert E. "Lost Jobs." Brookings Papers on Economic Activity, 1995:1, pp. 221-256.

Hall, Robert E. "Reorganization." Carnegie-Rochester Conference Series on Public Policy, June 2000, pp. 1-22.

Hall, Robert E. "Job Loss, Job Finding, and Unemployment in the U.S. Economy over the Past Fifty Years." NBER Working Paper 11678, September 2005.

Lucas, Robert, E. "On the Size Distribution of Business Firms." The Bell Journal of Economics, Autumn1978, 9(2), pp. 508-523.

Lucas, Robert, E. Models of Business Cycles, Oxford: Basil Blackwell, 1987.

Jensen, J. Bradford; McGuckin, Robert H. and Stiroh, Kevin J. "The Impact of Vintage and Survival on Productivity: Evidence from Cohorts of U.S. Manufacturing Plants." Economic Studies Series Working paper 00-06, Census of Bureau, May 2000.

Jovanovic, Boyan. "Selection and the Evolution of Industry." Econometrica, May 1982, 50(3), pp. 649-70.

Krusell, Per. and Smith, Anthony A. Jr. "Income and Wealth Heterogeneity in the Macroeconomy." Journal of Political Economy, 1998, 106(5), pp. 867-895.

Kydland, Finn E. and Prescott, Edward C, 1982. "Time to Build and Aggregate Fluctuations," Econometrica, vol. 50(6), pages 1345-70.

Mortensen, Dale and Pissarides,Christopher. "Job Creation and Job Destruction in the Theory of Unemployment." Review of Economic Studies, July 1994, 61(3), pp. 397-415.

Montgomery, Edward and Wascher, William. "Creative Destruction and the Behavior of Productivity over the Business Cycle." Review of Economics and Statistics, February 1998, 70(1), pp. 168-172. 
Pries, Michael J. "Persistence of Employment Fluctuations: a Model of Recurring Firm Loss." Review of Economic Studies, January 2004, 71(1), pp. 193-215.

Ramey, Garey and Watson, Joel. "Contractual Fragility, Job Destruction, and Business Cycles." Quarterly Journal of Economics, August 1997, 112(3), pp. 873-911.

Rust, John. "Using Randomization to Break the Curse of Dimensionality." Econometrica, May 1997, 65(3), pp. 487-516.

Rust, John. "Structural Estimation of Markov Decision Processes." Handbook of Econometrics, 1994, V IV.

Schumpeter, Joseph A. "Depressions." in Douglas Brown et al., Economics of the Recovery Program, New York, 1934, pp. 3-12.

Young, Eric R. "Approximate Aggregation: an Obstacle Course for the Krusell-Smith Algorithm." Florida University, 2002. 